\title{
Межмолекулярные взаимодействия в полиамидах с участием воды
}

\author{
С 2020 Селеменев В.Ф. ${ }^{1}$, Карпов С.И. ${ }^{1}$, Беланова Н.А. ${ }^{1}$, Рудакова Л.В. ${ }^{2}$, \\ Семенов В.Н. ${ }^{1}$, Кущев П.О.. ${ }^{1}$, Синяева Л.А. ${ }^{1}$ \\ ${ }^{1}$ Воронежский государственный университет, Воронеж \\ ${ }^{2}$ Воронежский государственный медицинский университет им. Н.Н. Бурденко, Воронеж
}

Поступила в редакцию 20.07.2020 г.

DOI: $10.17308 /$ sorpchrom.2020.20/2952

Впервые методом ИК-спектроскопии зафиксировано наличие в полиамиде-6 и в супрамолекулярном абсорбенте «Твердая вода» циклических структур, образованных карбоксильными группами в соседних параллельных цепочках, а также лактамных фрагментов, возникающих в результате таутомерных превращений (с участием амидных групп).

Установлена способность полиамидов поглощать фенол и его производные из водных растворов. Сорбция проявляет себя весьма эффективно, так как фенол образует с C=O-группами амид-

ных группировок более прочные водородные связи, чем связи -NHCO $\cdots \mathrm{H}_{2} \mathrm{O}$ и

Предложена концепция модификации в триаде взаимодействующих составляющих «водамицеллярный микрореактор с поверхностно активным веществом (ПАВ)-неподвижная фаза». Для суперабсорбента «Твердая вода» присуще то, что после его внесения в сухую почву и однократного полива, роль неподвижной фазы выполняет мицелла, модифицированная ПАВ. При этом поверхностно активное вещество проявляет себя и как кристаллит, и как жидкая фаза с ламинарной структурой.

Показано, что в трехкомпонентной модели главную роль играют коэффициент распределения вещества $\left(K_{M W}\right)$ между мицеллой и водой и коэффициент распределения вещества $\left(K_{S M}\right)$ между неподвижной фазой (НФ). Весьма скромная роль в рассматриваемой трёхкомпонентной модели отводится коэффициенту распределения вещества $\left(K_{S W}\right)$ между неподвижной фазой и водой, так как $K_{S W}$ на два порядка и более меньше по сравнению с $K_{M W}$.

Представлены данные о влиянии рН на образование мицелл амфотерными ПАВ. В кислых средах данные соединения существуют в катионной форме $(\mathrm{pH}<\mathrm{pI})$; в нейтральных средах (при $\mathrm{pH}=\mathrm{pI}$, где I - изоэлектрическая точка) в форме биполярных ионов; в средах с высокими значениями $\mathrm{pH}$ - в виде анионов ( $\mathrm{pH}>\mathrm{pI})$. В реакциях протолиза с индикаторами они проявляют себя как инициаторы перехода бензольных структур в хиноидные, что приводит к появлению в индикаторах цепей сопряжения (конъюгации) с чередующимися одинарными и кратными связями.

Приведены данные, показывающие влияние коэффициентов распределения в подвижной (ПФ) и неподвижной (НФ) фазах в тонкослойной хроматографии на величины константы протолиза $K_{a}$ разделяемых компонентов и на значение $\mathrm{pH}$ в мицеллярных реакторах.

Авторы статьи убеждены, что полиамиды займут наряду с другими полимерами достойное место как неподвижные фазы в плоскостной хроматографии и высокоэффективной жидкостной хроматографии.

Ключевые слова: полиамиды, межмолекулярные процессы, ИК-спектроскопия, УФ-спектроскопия.

\section{Введение}

Химия полиамидов своими целями, задачами и традициями тесно связана с биоорганической химией, молекулярной биологией, хроматографией. Сюда можно 
отнести формулировку идеи соучастия соседних групп в реакции у амидного центра; примеры выделения флавоноидов; азотсодержащих гетероциклических соединений; продуктов расщепления лигнина, аминокислот и пептидов [1-6].

Реакции, протекающие у амидного центра нельзя, конечно, рассматривать в отрыве от материала химии полиамидов в целом. Можно предположить, что предпочтительные направления и механизмы реакций контролируются структурой и конформацией всей молекулы полиамида. Соединения, называемые общим термином «амиды», могут содержать атомы, связывающие амидогруппу с остальными структурными фрагментами полимера. По этому признаку необходимо различать О- и Nсодержащие группировки. $\mathrm{N}$-группировки в зависимости от основности могут мутаротировать, подвергаться таутомерным превращениям. О-содержащие группы за счет образования Н-связей (внутри- и межмолекулярных) в большинстве случаев устойчивы к гидролизу и не меняют конфигурацию амидных центров. Однако, вопрос о влиянии амидных структур на межмолекулярные взаимодействия и на участие в этих процессах воды позволит уточнить механизм конформационных превращений в макромолекулах полимера, а также установить связь между положением полос в ИК-спектрах и структурой полиамидов. Последнее и явилось целью исследования в данной работе.

\section{Экспериментальная часть}

I. Межмолекулярные взаимодействия в полиамидах. Наиболее распространенными способами экспериментальной работы с полиамидами, пептидами и белками являются хроматографические и спектральные методы [1-8]. В методах распределительной (бумажной), тонкослойной, колоночной хроматографии использованы приемы и методики, представленные в $[1,6,7]$. В связи с тем, что объекты исследования относятся к природным сорбентам, их структурные, транспортные, регулятивные, генетически-информационные свойства изучались с применением известных биологических методов $[3,7,9]$. Гидратационные и межмолекулярные взаимодействия в полиамидах, белках и пептидах исследовались методами визуальной микроскопии $[6,11]$, УФ- и ИК-спектроскопии $[8,10,11]$.

Полиамиды получают поликонденсацией диаминов и дикарбоновых кислот или $\omega$-аминокарбоновых кислот. При синтезе полиамидов в их структуре могут оставаться не вступившие в реакцию мономеры. В этом случае в межмолекулярных взаимодействиях участвуют как ионы $-\mathrm{COO}^{-} ; \stackrel{+}{-} \mathrm{NH}_{2}$, так и неионогенные группы $-\mathrm{OH} ;>\mathrm{C}=\mathrm{O} ;>\mathrm{C}=\mathrm{N}$; $>\mathrm{N}^{+}-\mathrm{H}_{2}$. Структуру полиамидов определяют формулами, различающимися числом атомов углерода, расположенных в цепи между двумя атомами азота:

$$
\begin{gathered}
\left.\left[-\left(\mathrm{CH}_{2}\right)_{\mathrm{z}-1}-\mathrm{CONH}\right]_{\mathrm{n}} \text { или [-CONH-( }\left(\mathrm{CH}_{2}\right)_{\mathrm{x}}-\mathrm{NHCO}-\left(\mathrm{CH}_{2}\right)_{\mathrm{y}-2}\right]_{\mathrm{n}} \\
\text { Схема } 1
\end{gathered}
$$

В соответствии с числом этих атомов полиамиды именуют $-Z$ (найлон- $Z$ ) или полиамид-XY (найлон-XY). При этом макромолекула полиамида-Z полярна (в отличие от полиамида-XY) и для него различают параллельную и антипараллельную укладку цепей в полимере. Полосы поглощения в ИК-спектре полиамидов (рис. 1, табл. 1) имеют отчетливые характеристические максимумы амидных групп. Эти полосы от Амид I до Амид VII проявляются в виде колебаний нелинейного фрагмента

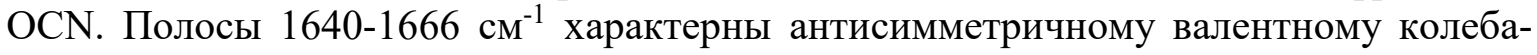
нию OCN-группы. Симметричные валентные колебания этой связи проявляются 
симметричным валентным колебанием при 1545-1556 см-1 (Амид II). Представляет интерес, что полоса при Амид II (1545-1556 $\left.\mathrm{cm}^{-1}\right)$ расщепляется на Амид II и Амид III (1263-1227 $\left.\mathrm{cm}^{-1}\right)$ согласно схеме 2:

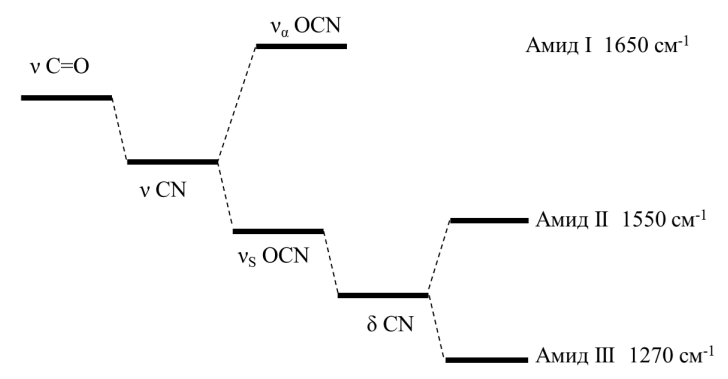

Схема 2

Пики Амид I соответствуют валентным колебаниям группы $\mathrm{C}=\mathrm{O}$, а в полосу Амид II вносят вклад колебания различных групп: NH-деформационные колебания (50\%), $\mathrm{CN}$-валентные колебания (40\%) и $\mathrm{C}=\mathrm{O}$-валентные колебания (10\%).
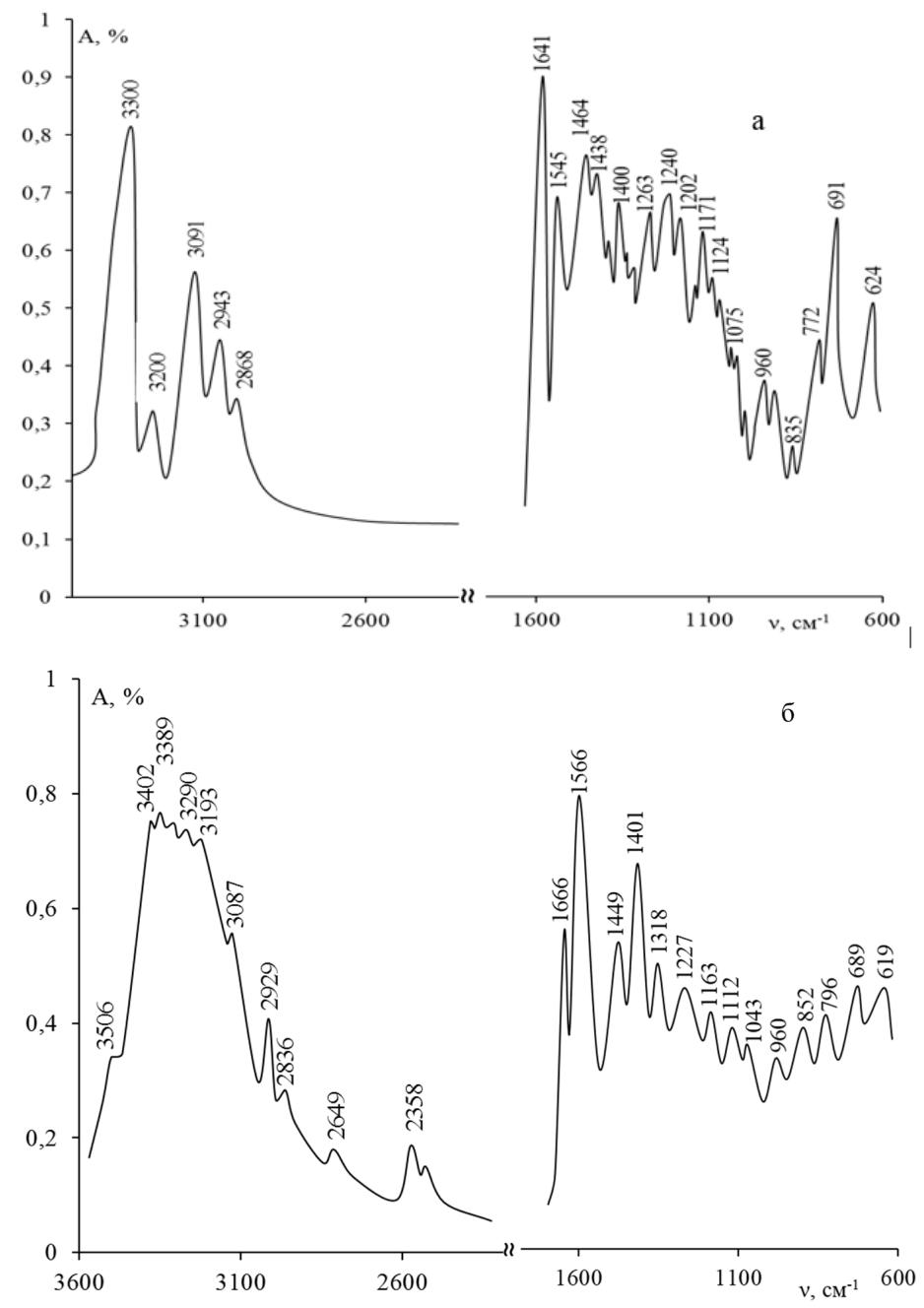

Рис. 1. ИК-спектры Полиамида-6 (а) и суперабсорбента «Твердая вода» (б)

Fig. 1. IR spectra of Polyamide-6 (a) and supersorbent "Soild water" (b)

$\mathrm{A} \cdot 10^{-2}-$ absorption, $\% ; v-$ vibrational frequency, $\mathrm{cm}^{-1}$. 
Полоса Амид III позволяет внести ясность в структурные и конформационные модификации полиамидов- $Z$, которые в силу своей полярности различаются параллельной $\alpha$ - и $\beta$ - укладкой цепей, соединенных Н-связями и полностью вытянутых. Эти полосы Амид III имеют две компоненты 1266-1202 см-1 $[1,2,5]$. В случае скручивания полимерных цепочек за счет поворота плоскости амидных групп относительно плоскости метиленовой цепи образуется $\gamma$-конформация. Полиамиды, в которых X и Y - четные числа (схема 1), имеют $\alpha$-структуру. Если X и Y - нечетные числа метиленовых групп, то имеет место $\gamma$-структура и полоса Амид III проявляется при 1270-1275 см-1. Таким образом, для исследуемых образцов полиамид-6 характерна $\alpha$-модификация (рис. 1 , табл. 1).

Таблица 1. Полосы поглощения в ИК-спектрах полиамида-6 и суперабсорбента «Твердая вода» $[2,5,6,8-12]$

Table 1. Absorption bands in the IR spectra of polyamide- 6 and the supersorbent "Solid water"

\begin{tabular}{|c|c|c|c|}
\hline \multicolumn{2}{|c|}{ Колебания $v, \mathrm{~cm}^{-1}$} & \multirow{2}{*}{$\Delta v, \mathrm{~cm}^{-1}$} & \multirow{2}{*}{ Отнесение полос } \\
\hline Полиамид-6 & «Твердая вода» & & \\
\hline- & 3506 & - & $\begin{array}{c}v \mathrm{H}_{2} \mathrm{O} \ldots \mathrm{H}_{2} \mathrm{O} \text { с } 3 \text { или } 2 \text { Н-связями; } \\
\mathrm{NH} \ldots \mathrm{OH}_{2}\end{array}$ \\
\hline- & $\begin{array}{l}3402 \\
3389\end{array}$ & - & $v \mathrm{H}_{2} \mathrm{O} \ldots \mathrm{H}_{2} \mathrm{O}$ с 4-мя или Н-связями \\
\hline 3300 & 3290 & 10 & $v_{\mathrm{s}} \mathrm{NH}$ \\
\hline 3200 & 3193 & 7 & Резонанс Ферми Амид I + Амид II c $v$ NH \\
\hline 3091 & 3087 & 4 & $\begin{array}{c}\text { Резонанс Ферми Амид II } \times 2 \text { c } v \text { NH; } \\
v \mathrm{C}=\mathrm{O} \ldots \mathrm{HN}\end{array}$ \\
\hline $\begin{array}{l}2943 \\
2868\end{array}$ & $\begin{array}{l}2929 \\
2836\end{array}$ & $\begin{array}{l}14 \\
32\end{array}$ & $\begin{array}{l}v_{\text {as }} \mathrm{CH}_{2} \text { вициальная; } \\
v_{\mathrm{s}} \mathrm{CH}_{2} \text { вициальная; }\end{array}$ \\
\hline- & 2649 & - & $\sigma=\alpha-$ ножничные $\mathrm{COOH} \ldots \mathrm{OH}_{2}$ \\
\hline- & 2358 & - & $\mathrm{N}$ в димерах $\mathrm{C}_{\mathrm{O}-\mathrm{H} \cdots \mathrm{O}}^{\mathrm{C}-}$ \\
\hline 1641 & 1666 & -25 & $\gamma_{\mathrm{w}}=\varphi$ веерные Амид I C $=\mathrm{O} \ldots \mathrm{H}_{2} \mathrm{O}$ \\
\hline 1545 & 1556 & -11 & $\gamma_{\mathrm{t}}=\psi$ маятник. Амид II CN... $\mathrm{H}_{2} \mathrm{O}$ \\
\hline $\begin{array}{l}1464 \\
1438 \\
1418\end{array}$ & $\begin{array}{c}1449 \\
- \\
-\end{array}$ & $\begin{array}{c}15 \\
- \\
-\end{array}$ & 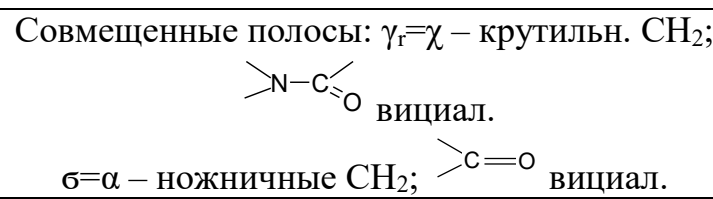 \\
\hline $\begin{array}{l}1400 \\
1374 \\
1316 \\
1263 \\
1240\end{array}$ & $\begin{array}{c}1401 \\
- \\
1318 \\
- \\
1227\end{array}$ & $\begin{array}{l}-1 \\
- \\
-2 \\
- \\
13\end{array}$ & $\begin{array}{c}\text { Совмещенные полосы: } \gamma_{\mathrm{w}}=\varphi \text { веерные } \mathrm{CH}_{2} \text {; } \\
\gamma_{\mathrm{t}} \text { маятник. } \mathrm{CH}_{2} \text {; } \\
\text { Частично ассоциированы с Амид III } \\
\text { ( } v \text { OCN c } \alpha \text { ножничн. } \mathrm{NH})\end{array}$ \\
\hline $\begin{array}{l}1263 \\
1240 \\
1202\end{array}$ & $\begin{array}{c}- \\
1227 \\
-\end{array}$ & $\begin{array}{c}- \\
13 \\
-\end{array}$ & Амид III \\
\hline 1171 & 1163 & -8 & $\gamma_{\mathrm{t}} \mathrm{CH}_{2}$ или $v \mathrm{C}_{\alpha} \mathrm{N}$ \\
\hline $\begin{array}{c}1029 \\
960\end{array}$ & $\begin{array}{c}1043 \\
960\end{array}$ & $\begin{array}{c}-14 \\
0\end{array}$ & v C-C ; Амид IV; $\Delta(\mathrm{CONH})$ \\
\hline $\begin{array}{l}835 \\
772\end{array}$ & $\begin{array}{l}852 \\
796\end{array}$ & $\begin{array}{l}-17 \\
-24\end{array}$ & $\gamma_{\mathrm{r}} \mathrm{CH}_{2}$ крутильн.; $\mathrm{CO}$ или $\mathrm{N}$ вициал. \\
\hline 691 & 689 & 2 & Амид V ( $\sigma=\alpha$ ножничн. $\mathrm{NH})$ \\
\hline $\begin{array}{l}624 \\
524\end{array}$ & $\begin{array}{l}619 \\
520\end{array}$ & $\begin{array}{l}5 \\
4\end{array}$ & Амид $\mathrm{V}(\boldsymbol{\sigma}=\alpha$ ножничн. $\mathrm{C}=\mathrm{O})$ \\
\hline
\end{tabular}

$\gamma_{\mathrm{r}}$ - крутильные; $\gamma_{\mathrm{t}}-$ маятниковые; $\gamma_{\mathrm{w}}-$ веерные; $\sigma-$ ножничные; $\mathrm{q}=\mathrm{Q}-$ валентные колебания 
Полоса Амид IV характеризуется плоскостными деформационными колебаниями фрагмента OCN, лежащими в интервале 1045-900 $\mathrm{cm}^{-1}$, что соответствует скелетным колебаниям амидных групп СONH в плоскости $[1,6,8]$ (табл. 1).

В наибольшей степени конформационно чувствительными являются максимумы Амид V и Амид VI (691 и 625-524 см-1 соответственно). Для Амида V полоса $691 \mathrm{~cm}^{-1}$ характерна в нашем случае $\alpha$-модификации полиамида- 6 и принадлежит ножничным колебаниям NH-группы перпендикулярно к плоскости амидной группировки. Полоса Амид VI характеризует деформационные колебания группы $\mathrm{C}=\mathrm{O}$, происходящие перпендикулярно к плоскости CONH-групп [1, 10-12].

Таким образом, на основании анализа ИК-спектров можно утверждать, что для полиамида-6 характерна $\alpha$-модификация, подтверждаемая наличием колебаний в группировках Амид I-Амид VI. Установлено межмолекулярное взаимодействие амидных группировок с молекулами воды и $\mathrm{CH}_{2}$ - метиленовыми группами. Подтверждено, что максимумы при 3200 и $3091 \mathrm{~cm}^{-1}$ обусловлены резонансом Ферми валентных колебаний NH-группы, а также обертонами (или комбинационными колебаниями) Амид I и Амид II. В представленных ИК-спектрах полиамида-6 четко проявляются полосы при 1438, 1374, 1029, 772 см$^{-1}$, свидетельствующие о их принадлежности к конформационным пикам, позволяющим отнести исследуемый полимер к гош-форме [1-5].

II. Полиамиды со свойствами адсорбента. Наряду с конформационными, полиамиды проявляют сорбционные свойства, что позволяет рассматривать механизм хроматографических процессов и хроматографическое разделение органических соединений на полиамидных полимерах методами колоночной и планарной хроматографии. Полиамиды обладают как распределительными, так и адсорбционными свойствами. Карбоксиамидная группа $\left(-\mathrm{CONH}_{2}-\right)$ в полиамидах способна участвовать в донорно-акцепторных взаимодействиях и является адсорбционно-активной. Полиамидные фазы особенно эффективны для разделения и идентификации фенолов, флавонов, таннинов, нитрофенолов, спиртов, карбоновых кислот, производных аминокислот и пептидов. Расстояние и поворотные изомеры $\mathrm{CH}_{2}$-цепи, регулируемые количеством гидрофобных $\mathrm{CH}_{2}$-групп, которые вносят вклад в механизм разделения, являются определяющими при гидрофобных взаимодействиях реактантов с цепями полиамида. Результатом вышеописанных реакций является возможность использования полиамидов как в нормально-фазовой, так и в обращенно-фазовой ТСХ $[12,13]$.

На рис. 2 приведена изотерма сорбции фенола из водного раствора на порошке полиамида. Из рисунка следует, что при малых концентрациях фенола наблюдается линейная зависимость между сорбцией и концентрацией реактанта в растворе. Эта зависимость соответствует равновесному распределению фенола, с коэффициентом распределения 12.0-12.4. В дальнейшем кривая (рис. 2а) не стремится к предельному значению, как в классической адсорбции, а имеет вид асимптоты и становится все более крутой, что означает сильное связывание фенола полиамидом $[11,14]$. Возможны два пути поглощения фенола:
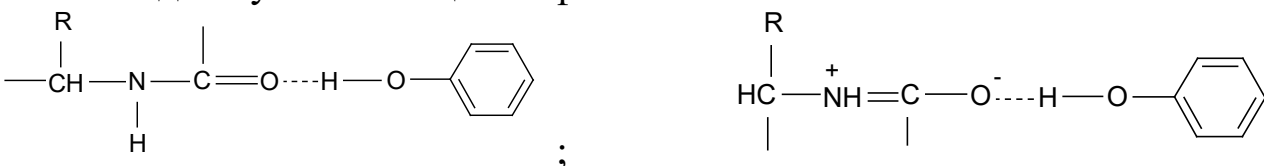

Такое водородное связывание между фенолом и амидной группой происходит за счет взаимодействия фенольной и ОН-группы с кислородом карбонильного фрагмента амидного звена полиамидной цепочки. Наличие таких ассоциатов подтверждается появлением новых максимумов 2646; 2500; 1826; $893 \mathrm{~cm}^{-1}$; смещением валентных колебаний при 3200; 3091; 2943; 1075;1029 см-1 в коротковолновую область (пики 3166; 3067; 2936; 1072; 1016 см$^{-1}$ ) и смещением полос поглощения деформаци- 
онных колебаний при 2868; 1641; 1545; 1418; 1240;1171; 1075; 1029; 691; $624 \mathrm{~cm}^{-1}$ в длинноволновую область $(2850 ; 1600 ; 1538 ; 1406 ; 1228 ; 1168 ; 1072 ; 1016 ; 684$; $620 \mathrm{~cm}^{-1}$ соответственно) (табл. 2, рис. 3). Поглощение фенола в данном случае можно рассматривать как один из вариантов фронтальной хроматографии $[1,6,7]$, когда удается выделить из смеси только один реактант (рис. 2a).

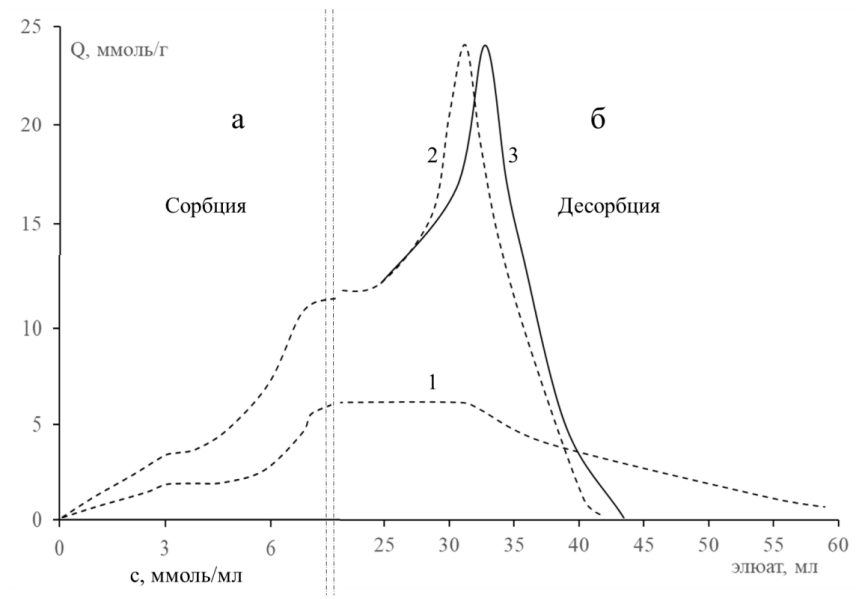

Рис. 2. Изотерма сорбции фенола на полиамиде (а) и десорбция реактанта различными растворителями (б): 1 - вода; 2 - 50\% этанол; $3-20 \%$ ацетон.

Fig. 2. Isotherm of phenol sorption on the polyamide (a) and the desorption of the reactant by various solvents (b). $\mathrm{Q}-\mathrm{mmol} / \mathrm{g}$ of the sorbent; $\mathrm{C}-\mathrm{mmol} / \mathrm{cm}^{3}$ of the solution. 1 - water; $2-50 \%$ ethanol; $3-20 \%$ acetone.

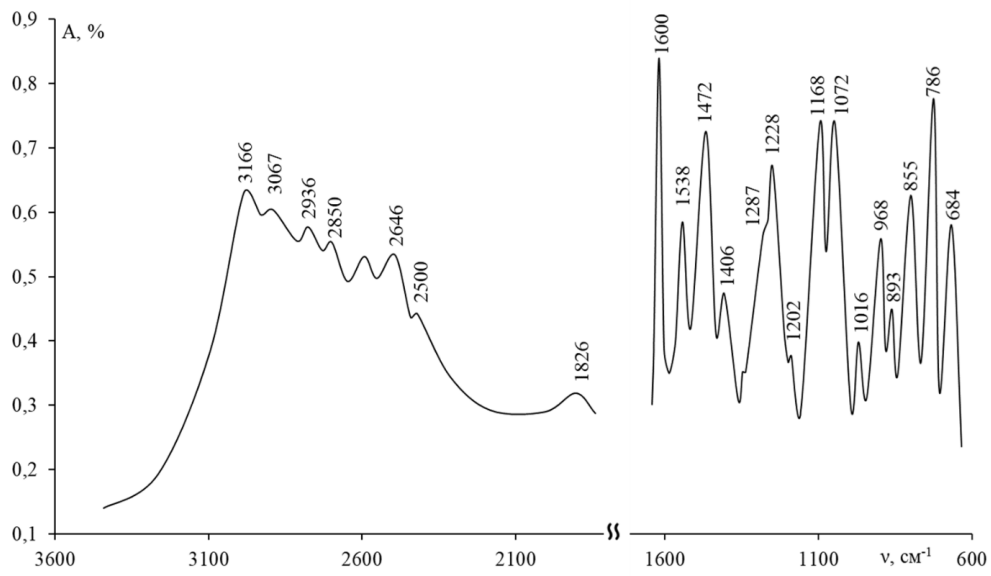

Рис. 3. ИК-спектр полиамида, сорбировавшего фенол

Fig. 3. IR spectrum of the polyamide that absorbed phenol. $\mathrm{A} \cdot 10^{-2}$ - absorption, $\% ; v-$ vibrational frequency, $\mathrm{cm}^{-1}$.

Между тем, процесс регенерации полиамида после поглощения фенола, позволяет отнести его к элюентному варианту хроматографического выделения целевого вещества (рис. 2б). Наиболее эффективна десорбция фенола растворами этанола и ацетона. Этот процесс можно рассматривать как реакцию вытеснения (элюции) фенола реагентами, способными образовывать более прочные связи по сравнению с Н-ассоциатами амидной группы с фенолом:

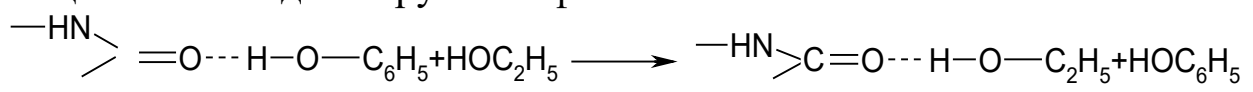


Таблица 2. Полосы поглощения в ИК-спектрах полиамида, сорбировавшего фенол [11-13]

Table 2. Absorption bands in the IR spectra of the polyamide which absorbed phenol

\begin{tabular}{|c|c|c|c|}
\hline \multicolumn{2}{|c|}{ Колебания $v, \mathrm{~cm}^{-1}$} & \multirow{2}{*}{$\Delta v, \mathrm{~cm}^{-1}$} & \multirow{2}{*}{ Отнесение полос } \\
\hline Полиамид-6 & Полиамид-6-фенол & & \\
\hline 3300 & - & - & $v_{\mathrm{s}} \mathrm{NH}_{3}$ \\
\hline 3200 & 3166 & 34 & Резонанс Ферми Амид I + Амид II c v NH \\
\hline 3091 & 3067 & 24 & $\begin{array}{c}\text { Резонанс Ферми Амид II } \times 2 \text { c } v \text { NH; } \\
\text { N C }=\mathrm{O} \ldots \mathrm{HN}\end{array}$ \\
\hline 2943 & 2936 & 9 & $v_{\text {as }} \mathrm{CH}_{2}$ вициальная \\
\hline 2868 & 2850 & 18 & $\begin{array}{c}\text { ОН валент. колеб. Н-связи ОН...NH; } \\
v_{\mathrm{s}} \mathrm{CH}_{2} \text { вициальная }\end{array}$ \\
\hline- & 2646 & - & $v \mathrm{HN}-\mathrm{C}=\mathrm{O}--\mathrm{HO}-\mathrm{C}_{6} \mathrm{H}_{5}$ \\
\hline- & 2500 & - & $v-\stackrel{+}{\mathrm{H}}=\stackrel{+}{\mathrm{C}}-\mathrm{O}^{-}-\mathrm{HO}-\mathrm{C}_{6} \mathrm{H}_{5}$ \\
\hline- & 1826 & - & $\begin{array}{c}\text { Совмещенные колебания: Обертон б ножн. } \\
+\begin{array}{c}+ \\
v-\mathrm{H}^{+}=\mathrm{C}-\mathrm{O}^{-} \cdots \mathrm{HO}^{-}-\mathrm{C}_{6} \mathrm{H}_{5}\end{array} \\
\text { и валентные } v \mathrm{C}=\mathrm{O} \text { в } \gamma \text {-лактонах }\end{array}$ \\
\hline 1641 & 1600 & 41 & $\begin{array}{c}\text { Совмещенные полосы колебаний } \gamma_{\mathrm{w}} \\
\text { веерные Амид I C=O }=\mathrm{H}_{2} \mathrm{O} ; \\
\text { и валентных } v \quad \mathrm{HN}-\mathrm{C}=\mathrm{O}-\mathrm{HO}-\mathrm{C}_{6} \mathrm{H}_{5}\end{array}$ \\
\hline 1545 & 1538 & 7 & 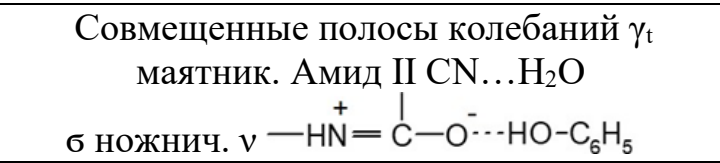 \\
\hline $\left.\begin{array}{l}1464 \\
1418 \\
1400\end{array}\right\}$ & $\begin{array}{c}1472 \\
1406 \\
-\end{array}$ & $\begin{array}{l}-8 \\
12 \\
-\end{array}$ & $\begin{array}{c}\text { Совмещенные колебания } \gamma_{\mathrm{r}} \text { крутил. } \mathrm{CH}_{2} \text {; } \\
\text { вициал. }-\mathrm{N}-\mathrm{C}=\mathrm{O} \\
\text { б ножничн. } \mathrm{CH}_{2} \text {; вициал. } \geq_{\mathrm{N}-\mathrm{C}=\mathrm{O}}\end{array}$ \\
\hline $\left.\begin{array}{l}1374 \\
1316 \\
1263 \\
1240\end{array}\right\}$ & $\begin{array}{c}1358 \\
1287 \\
- \\
1228\end{array}$ & $\begin{array}{l}16 \\
29 \\
- \\
12\end{array}$ & $\begin{array}{c}\gamma_{\mathrm{w}} \text { веерн. } \mathrm{CH}_{2} ; \gamma_{\mathrm{t}} \text { маятн. } \mathrm{CH}_{2} \text { частично } \\
\text { ассоциц. с Амид III } \\
\text { Валентные ( }\left(v_{\mathrm{s}} \mathrm{OCN} \text { с б н ножнич. NH) }\right.\end{array}$ \\
\hline $\left.\begin{array}{l}1263 \\
1240 \\
1202\end{array}\right\}$ & $\begin{array}{l}- \\
1228 \\
1202\end{array}$ & $\begin{array}{c}- \\
12 \\
0\end{array}$ & Амид III; б С-ОН в фенолах \\
\hline 1171 & 1168 & 3 & Совмещенные полосы $\gamma_{\mathrm{t}} \mathrm{CH}_{2} ; v \mathrm{C}_{\mathrm{a}} \mathrm{N}$ \\
\hline 1124 & - & - & Валентные $v$ C-C \\
\hline 1075 & 1072 & 3 & Валентные $v \mathrm{C}_{\alpha} \mathrm{N}$ \\
\hline $\left.\begin{array}{l}1029 \\
960\end{array}\right\}$ & $\begin{array}{c}1016 \\
968\end{array}$ & $\begin{array}{l}13 \\
-8\end{array}$ & $\begin{array}{c}\text { Совмещенные полосы валентных v C-C; } \\
\text { Амид IV и } \Delta(\mathrm{CONH})\end{array}$ \\
\hline $\begin{array}{c}- \\
835\end{array}$ & $\begin{array}{l}893 \\
855\end{array}$ & $\begin{array}{c}- \\
-20\end{array}$ & $\begin{array}{c}\text { Совмещенные полосы } \gamma_{\mathrm{r}} \mathrm{CH}_{2} \text { крутильных; } \\
\mathrm{C}=\mathrm{O} \text { и N-вициальных }\end{array}$ \\
\hline 772 & 786 & -14 & $\gamma_{\mathrm{r}} \mathrm{CH}_{2}$ \\
\hline 691 & 684 & 7 & $\begin{array}{c}\text { Совмещенные полосы Амид V и } \\
\text { б ножничн. NH }\end{array}$ \\
\hline $\left.\begin{array}{l}624 \\
524\end{array}\right\}$ & $\begin{array}{c}620 \\
-\end{array}$ & $\begin{array}{l}4 \\
-\end{array}$ & $\begin{array}{c}\text { Совмещенные полосы Амид VI и } \\
\text { б ножничн. } \mathrm{C}=\mathrm{O}\end{array}$ \\
\hline
\end{tabular}


Следует отметить появление полосы поглощения $1826 \mathrm{~cm}^{-1}$, характерную для $\mathrm{C}=\mathrm{O}$ в $\gamma$-лактонах.<smiles>C=CCCC(=O)OC(C)O</smiles><smiles>CC(C)CCCC(=O)CO</smiles>

Эти циклы образуются в результате таутомерных превращений с участием $-\mathrm{CONH}_{2}$-групп.

Таким образом, процесс регенерации полиамида оказывается всегда совмещенным с элюционным процессом выделения фенола этанолом и ацетоном из фазы сорбента.

III. Микрореакторы ПАВ в хроматографических процессах. Полиамиды являются эффективными сорбентами при использовании мицеллярных подвижных фаз в тонкослойной хроматографии. Как отмечено выше, в мицеллярной ТСХ процессы взаимодействия и разделения смеси соединений происходят в микрореакторах с участием поверхностно-активных веществ (ПАВ) [8, 10-12]. Хорошую разделительную способность пластин (как на прямых неподвижных фазах в поверхностных слоях Силуфола, Сорбфила, целлюлозы так и на обращенных НФ Плазмахрома, Силикагеля с привитой фазой $\mathrm{C}_{18}$ ) объясняют относительно слабой адсорбцией ПАВ. В наибольшей мере, по сравнению с вышеприведенными НФ, слабой адсорбцией ПАВ обладают полиамидные мицеллярные пластины. Вследствие этого на полиамидах наблюдается относительно постоянная концентрация мицелл ПАВ в ПФ при ее продвижении вдоль поверхности сорбента, что способствует хорошей воспроизводимости определений.

Разумеется, химическая устойчивость НФ на пластинах ТСХ зависит от природы ПАВ, образующих модифицированную подвижную фазу. Установлено также [10-12, 19-30], что при движении подвижной фазы, содержащей ПАВ, по слою сорбента в хроматографической колонке, или в слоях хроматографической пластины в связи с адсорбцией гидрофобных ионов или молекул ПАВ происходит динамическая модификация поверхности неподвижной фазы. Следствием модифицирования неподвижной фазы выступают абсолютное изменение ее свойств и исходного режима хроматографирования. На этой (третьей) особенности неподвижной фазы в МЖХ остановимся подробнее.

Адсорбция анионных ПАВ происходит в основном по гидрофобному механизму и, соответственно, движущей силой процесса выступают гидрофобные взаимодействия между углеводными радикалами привитого слоя сорбента и ПАВ $[3,5$, 14]. В результате поверхность полимера заряжается отрицательно благодаря гидрофильным группам анионных ПАВ и неподвижный слой приобретает способность к катионному обмену с ионами подвижной фазы (рис. 4a). Результатом происходящих изменений является вариация обращенно-фазового режима хроматографирования на нормально-фазовый и порядок элюирования анализируемых веществ в аналите также меняется на обратный (рис. 4б).

Если на гидрофобной поверхности адсорбируются катионные ПАВ, то становится возможной реализация двух механизмов взаимодействия: гидрофобного и электростатического. Первый из них аналогичен случаю анионных ПАВ (то есть реализуется за счет гидрофобных взаимодействий). Второй происходит за счет ассоциации между немодифицированными диссоциирующими силанольными группами поверхности силикагеля и катионными группами ПАВ (рис. 4б) [15]. Конечный результат зависит от модификации слоя, то есть от соотношения алкилированных и неалкилированных поверхностных силанольных групп.

В отличие от обращенных фаз адсорбция ионных ПАВ на нормальной фазе немодифицированного и гидрофильно-модифицированного силикагеля способствует 
гидрофобизации сорбента, который становится обращенно-фазовым [12-14]. Результатом таких взаимодействий является изменение нормально-фазового режима хроматографирования на обращенно-фазовый. На рис. 5 в качестве примера вышеописанного явления приведены хроматограммы ксиленолового оранжевого на Силуфоле с двумя различными ПФ [15], когда соответствующим образом меняется порядок элюирования веществ.

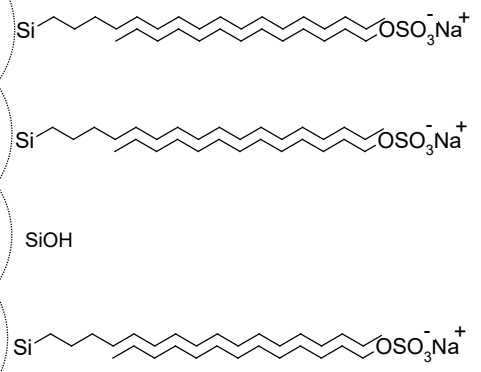

a
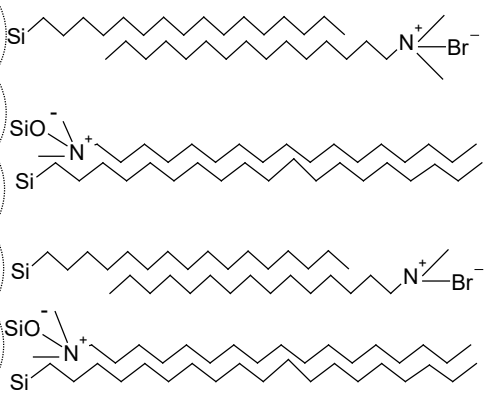

б

Рис. 4. Возможные варианты адсорбции ПАВ на октадецилсилане: a - додецилсульфата натрия (гидрофобная адсорбция); б - гидрофильногидрофобная адсорбция на примере бромида цетилтриметиламмония [13-14]

Fig. 4. Options of SAM adsorption on octadecylsilane: a - sodium dodecyl sulphate (hydrophobic adsorption); $b$ - hydrophobic-hydrophilic adsorption based on the example of cetyltrimethylammonium bromide

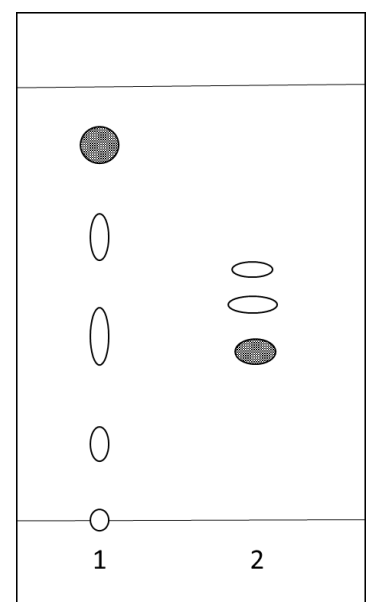

Рис. 5. Хроматограммы ксиленолового оранжевого на Силуфоле

1 - ПФ является водный раствор додецилсульфата натрия; 2 - ПФ является смесь н-бутанола, 25\%-ного раствора $\mathrm{NH}_{4} \mathrm{OH}$, изопропанола (5:5:3). Зоны красителя заштрихованы.

Fig. 5. Chromatograms of Xylenol orange on Silufol. 1 - SP is a dodecyl sulphate aqueous solution; 2 - SP is the mixture of n-butanol, $25 \%$ solution of $\mathrm{NH}_{4} \mathrm{OH}$, and isopropanol (5:5:3). The colouring agent zones are crosshatched.

Наиболее часто в качестве модификаторов неподвижной фазы применяют ионные ПАВ, которые при адсорбции на твердой поверхности ориентируются вертикально. В отличие от ионных ПАВ, неионные оксиэтилированные цепи модификатора располагаются горизонтально к поверхности и в меньшей мере способны модифицировать неподвижную фазу [9-16]. Сильное влияние (независимо от природы адсорбента) на модификацию поверхности и формы изотерм адсорбции ПАВ оказывают природа и структура ПАВ, $\mathrm{pH}$, ионная сила водного раствора, температура, присутствие органических растворителей и добавок, одновременное нахождение в 
растворе нескольких разновидностей поверхностно активных веществ. Весьма заметно на адсорбцию анионных ПАВ влияют неионные, вызывая появление адсорбционного максимума на изотерме (табл. 3). Существует мнение, что превышение концентрации ПАВ величин ККМ, меняются относительные концентрации молекул (или ионов) ПАВ в растворе в связи с образованием смешенных мицелл.

Таблица 3. Влияние изменения свободной энергии адсорбции $\left(-\Delta \mathrm{G}^{\circ} \mathrm{H}\right)$ и мицеллообразования $\left(-\Delta \mathrm{G}_{\text {acc }}^{\circ}\right)$, соотношения эффективных поверхностей соответственно сорбента $\left(\mathrm{S}_{\mathrm{c}}\right)$ и мицеллярной фазы $\left(\mathrm{S}_{\mathrm{M}}\right)$ системы на формы изотерм адсорбции из водных растворов

Table 3. The influence of the change in the free energy of adsorption $\left(-\Delta \mathrm{G}^{\circ}{ }_{\mathrm{H}}\right)$ and formation of micelles $\left(-\Delta \mathrm{G}^{\circ}\right.$ acc $)$, the proportion of the effective surfaces of the sorbent $\left(\mathrm{S}_{\mathrm{c}}\right)$ and the micellar phase $\left(S_{M}\right)$ of the system on the form of the isotherms of adsorption from aqueous solutions

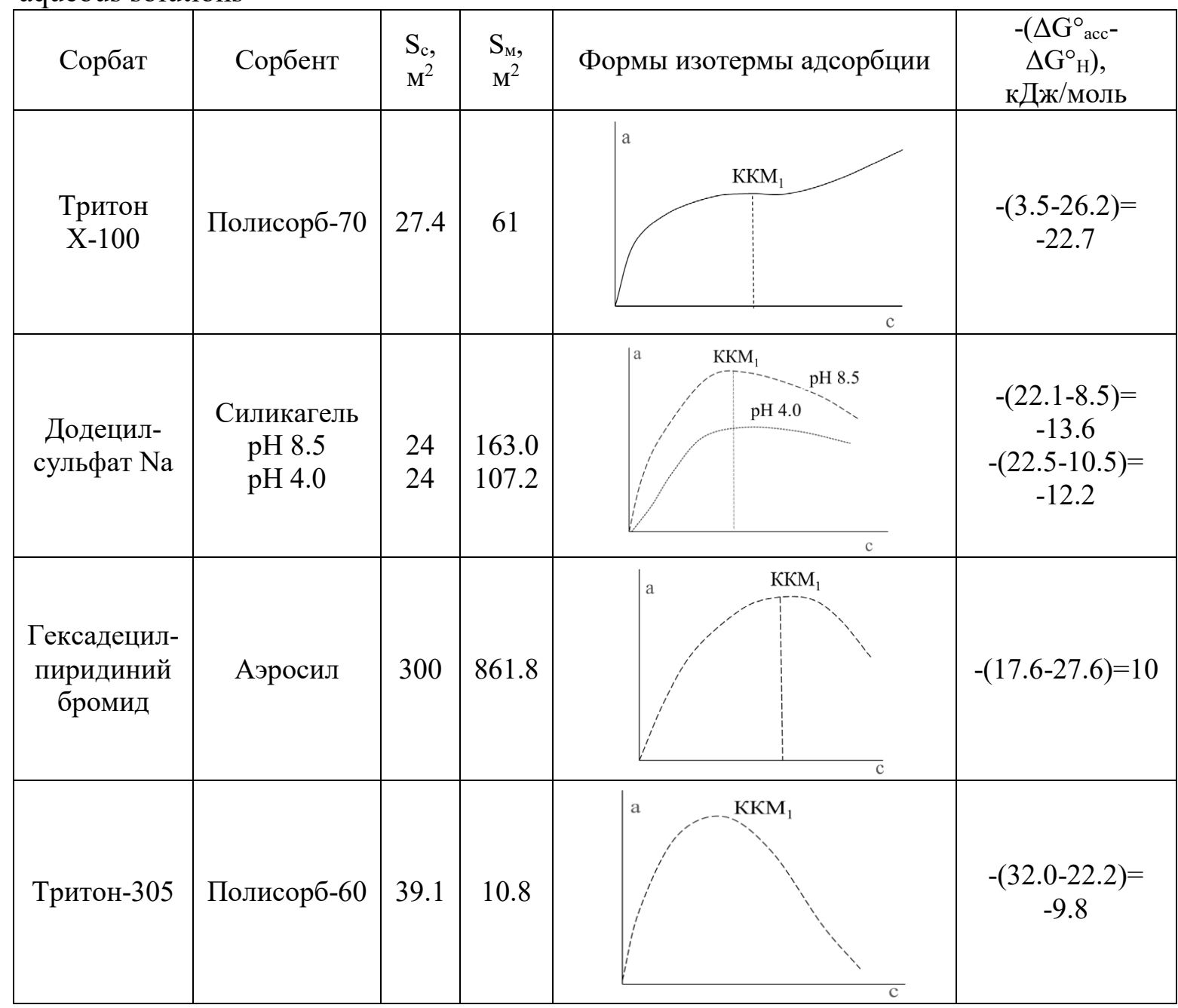

IV. Мицеллярные жидкие фазы в экологии. Мицеллярные микрореакторы на основе поверхностно активных веществ находят широкое применение в анализе минеральных и органических токсикантов. Мицеллярные подвижные фазы (МПФ) с участием мицеллярных ПАВ используются также для изучения механизма удерживания веществ на нормальных и обращенно-фазовых носителях и для установления способов удерживания во взаимосвязи с гидрофобностью определяемых веществ [7, 13-16]. Выборка отдельных примеров применения мицеллярных вариантов ТСХ и ВЭЖХ приведена в таблице 4. 
Таблица 4. Основные хроматографические параметры разделения органических веществ методом тонкослойной хроматографии в мицеллярных растворах ПАВ $[14,15]$ Table 4. Main chromatographic parameters of the separation of organic substances by means of thin-layer chromatography in micellar solutions of SAM

\begin{tabular}{|c|c|c|c|}
\hline $\begin{array}{c}\text { Разделяемые со- } \\
\text { единения }\end{array}$ & Неподвижная фаза & Подвижная фаза & Детектирование \\
\hline п, м-нитрофенол & $\begin{array}{c}\text { Полиамид-6 UV } 254 \\
\text { импренгированный } \\
\text { ПАВ }\end{array}$ & ЦТАБ; ЦТАХ; ДДС & $\begin{array}{c}\text { УФ } 218 \text { нм - } \\
\text { ДДС; ЦТАБ, } \\
\text { ЦТАХ - } 226 \text { нм }\end{array}$ \\
\hline 20 аминокислот & $\begin{array}{c}\text { Полиамид-6 UV } 254 ; \\
\text { силанизированный } \\
\text { силикагель }\end{array}$ & $\begin{array}{l}1.3 \text { М ДОСС в циклогек- } \\
\text { сане (обратные мицеллы) }\end{array}$ & $\begin{array}{c}0.1 \% \\
\text { p-p нингидрина }\end{array}$ \\
\hline $\begin{array}{c}\text { Ацетаминофен } \\
\text { (парацетамол) }\end{array}$ & Nucleosil C-18 & $\begin{array}{c}0.05 \text { М ДДС - 3.0\% } \\
\text { 1-пропанол; Амп; } \\
0.02 \text { мкг } / \mathrm{cm}^{3} \\
\end{array}$ & \\
\hline $\begin{array}{l}\text { Никотин (I), } \\
\text { котинин (II) }\end{array}$ & Econospher CN & $\begin{array}{c}0.2 \mathrm{M} \mathrm{ДДС}-3 \% 2- \\
\text { пропанол с } \mathrm{pH} 4.6 \text { и } 40^{\circ} \mathrm{C}\end{array}$ & $\begin{array}{c}\text { УФ } 260 \mathrm{HM} ; \\
0.2 \text { (I); } \\
0.1 \text { (II) } \mathrm{MКг} / \mathrm{cm}^{3}\end{array}$ \\
\hline $\begin{array}{l}\text { Кодеин (I), } \\
\text { морфин (II) }\end{array}$ & $\begin{array}{l}\mu \text {-Bondapak C-18 и } \\
\text { Supelcosil LC-CN }\end{array}$ & $\begin{array}{c}0.02-0.05 \text { М ДДС - } \\
10 \% \text { пропанол } \\
\end{array}$ & $\begin{array}{c}\text { ФЛ } 219 / 300 \mathrm{нм} \\
0.3(\mathrm{I}, \mathrm{II}) \mathrm{MКг} / \mathrm{cm}^{3} \\
\end{array}$ \\
\hline Пролин & $\mathrm{C} 18$ & $\begin{array}{c}0.03 \mathrm{M} \mathrm{ДДС-} \\
\text { 8\% 1-пропанол в } 0.01 \mathrm{M} \\
\text { ацетатном буферном рас- } \\
\text { творе рН } 5.3 \text { и } 40^{\circ} \mathrm{C} . \\
\text { Предкол. дериват. С } \\
0.001 \mathrm{M} \mathrm{Cu}^{2+}\end{array}$ & 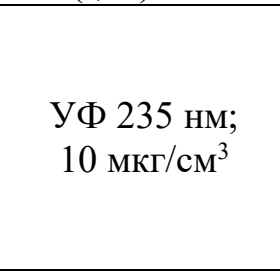 \\
\hline $\begin{array}{l}\text { Цинк, медь, мар- } \\
\text { ганец, кобальт, } \\
\text { никель }\end{array}$ & Inertsil ODS-2 & $\begin{array}{c}0.0945 \text { М ДДС в } 0.0684 \text { М } \\
\text { тартр. буф. р-ре рН } 4.2 . \\
\text { постколоночная деривати- } \\
\text { зация с пиридилазорезор- } \\
\text { цином }\end{array}$ & УФ 540 нм \\
\hline $\begin{array}{c}\text { Имидазол, } \\
\text { метилимидазол }\end{array}$ & Nucleosil 100-5 C8 & $\begin{array}{c}\text { Метанол }-0.02 \text { М р-р калия } \\
\text { дегидрофосфата - вода } \\
(32.5: 25: 42.5) \text { с } 0.005 \text { ДДС }\end{array}$ & УФ 215 нм \\
\hline $\begin{array}{c}\text { Лидокаина } \\
\text { гидрохлорид (I), } \\
\text { толперизон }\end{array}$ & $\mathrm{C} 18$ & $\begin{array}{c}0.075 \text { М ДДС - } \\
7.5 \% \text { изопропанола }\end{array}$ & $\begin{array}{c}\text { УФ } 210 \text { нм; } \\
0.73(\mathrm{I}) \\
1.43 \text { (II) нг/дм }{ }^{3}\end{array}$ \\
\hline Кофеин & Spherisorb ODS-2 & $\begin{array}{c}0.05 \mathrm{M} \mathrm{ДДС-} \\
1.5 \% \text { 1-пропанол - } 0.01 \mathrm{M} \\
\text { буфер, раствор фосфатн. } \\
\text { буф. p-ра рН } 7.0\end{array}$ & $\begin{array}{l}\text { УФ } 273 \mathrm{нм} ; \\
6.0 \mathrm{мкг} / \mathrm{cm}^{3}\end{array}$ \\
\hline
\end{tabular}

Сравнение модификации подвижных и неподвижных фаз в ТСХ И ВЭЖХ мицеллами ПАВ позволяет сделать определенные заключения:

1) Использование наногетерогенных мицеллярных подвижных фаз с элементами самоорганизации позволяет одновременно разделять полярные и неполярные аналиты;

2) Наблюдается существенное уменьшение объемов использования канцерогенных объемов использования канцерогенных и токсичных органических растворителей;

3) Водно-мицеллярные элюенты позволяют в динамическом режиме модифицировать прямую и обращенную фазы, а также сорбенты средней полярности (полиамидные и полипептидные сорбенты) ионными ПАВ; 
4) Разделение в модифицированных фазах менее эффективно, но более селективно, чем при использовании классических водно-органических ПФ и неводных подвижных фаз;

5) В мицеллярной ВЭЖХ в большинстве случаев эффективны неполярные сорбенты [3, 4, 13-16].

Для описания равновесных процессов на поверхности сорбента и в колонке мицеллярной жидкостной хроматографии существует несколько моделей, одна из которых предложена Армстронгом и Ноумом [13-14]. Достоинством этой модели является то, что авторы учитывают не только распределение сорбата между неподвижной и подвижной фазами, но и дополнительно внутри самой подвижной фазы между водой и мицеллами ПАВ. Наличие этого второго равновесия отличает МЖХ от классической жидкостной хроматографии с водно-органическими элюентами [1416]. Некоторая ограниченность модели Армстронга-Ноума, вызванная тем, что в ней фактически не учитывается изменение баланса между полярными и лиофильными частями ПАВ, может дополнена изменениями фазовых превращений в ПАВ в зависимости от концентрации [17]. Кроме этого, в модели Армстрога-Ноума отсутствуют представления о том, что необходимо считать неподвижной фазой, мицеллярной фазой, если процессы мицеллобразования с участием ПАВ происходят в фазе полимерного сорбента. Подобные взаимодействия вступают в силу, когда в качестве объекта исследования рассматриваются супрамолекулярные абсорбенты типа «Твердая вода», характеризующиеся значительным поглощением воды (до 500 л на один кг сорбента) [18-19]. Эти адсорбенты синтезированы на основе биодеградирующих полисахаридов (крахмала, хитозана, пектина), акриламида в метакриловой кислоте или $\mathrm{N}, \mathrm{N}$-метилен-бис-акриламида и Редокс-инициирующей системы $\mathrm{H}_{2} \mathrm{O}_{2}+\mathrm{Fe}_{2}\left(\mathrm{SO}_{4}\right)_{3}[12$, 19]. Содержат подобные адсорбенты как неиногенные группы (гидроксильные полисахаридных звеньев, амидные $\stackrel{\mathrm{O}=\mathrm{C}-\mathrm{NH}}{\mathrm{l}}$ - группы), ионы $\left(-\mathrm{COO}^{-} ;-\mathrm{N}^{+} \mathrm{H}_{2}\right)$ и различной длины углеводородные цепочки. Поэтому для суперабсорбента «Твердая вода» являются характерными ламеллярная (на отдельных участках цепи) и кристаллическая фаза. Таким образом, можно считать, что суперабсорбент способен образовывать внутри гранул фазы ПАВ в диапазоне между кристаллом и кристаллической ламеллярной структурами, проявляя супрамолекулярные самоорганизующиеся свойства с участием фрагментов ионоподобных поверхностно-активных веществ $[14,17,19]$. Помещенные в почву (для обеспечения влагой корневой системы растений) сухие гранулы суперабсорбента выступают в двух ипостасях. При однократном обильном поливе гранулы играют роль неподвижной фазы, которая кардинально отличается от таковой в общепринятой трехфазной модели, так как мицеллы ПАВ (I) находятся не вне неподвижной фазы (рис. 6a), а соседствуют внутри неподвижной фазы с участками ионов - $\mathrm{COO}^{-}$и $-\mathrm{N}^{+} \mathrm{H}_{2}$, которые способствуют образованию молекулярного раствора ПАВ (II).

Хроматографическое поведение сорбата хотя и определяется в мицеллярной подвижной фазе тремя коэффициентами, но значение коэффициента распределения $K_{S M}$ в отличие от общепринятой модели имеет две составляющие $K_{S M}$ и $K_{S M}{ }^{\prime \prime}$, что необходимо учитывать при расчете константы связывания ионов сорбата с мицеллами ПАВ. Сделав допущение, что при наступлении равновесия можно ввести вместо двух констант $K_{S M^{\prime}}$ и $K_{S M}{ }^{\prime \prime}$ общую константу $K_{S M}$, которая учитывает распределение сорбата между неподвижной фазой и сорбатом. 


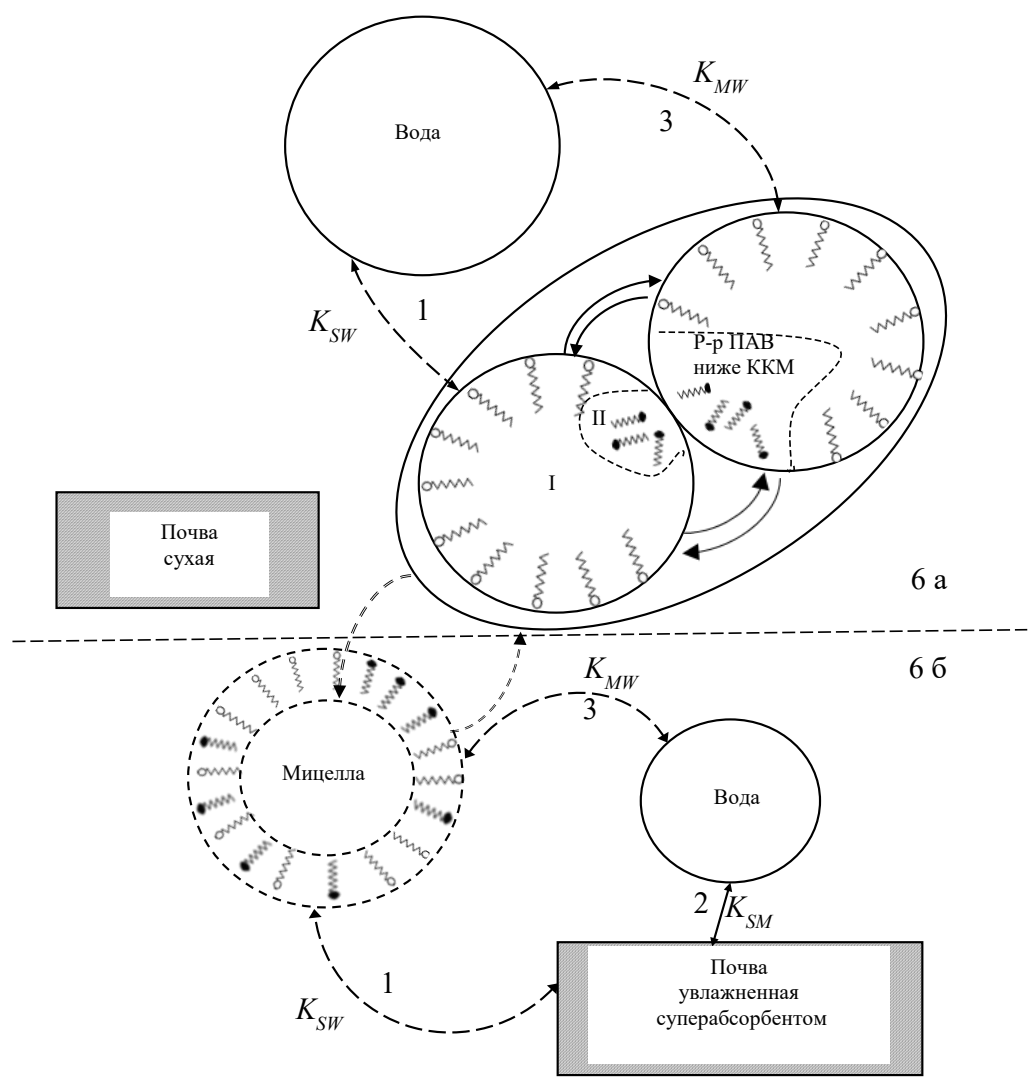

Рис. 6. Трехфазная модель мицеллярной жидкостной хроматографии в системе: неподвижная фаза-мицелла ПАВ-вода. Роль неподвижной фазы и мицеллы до полива смещены в матрице суперабсорбента «Твердая вода» (рис. 6а). После полива неподвижной фазой стала почва (рис. 6б), а роль мицелл выполняют дифильные фрагменты в структуре абсорбента

Fig. 6. A three-phase model of micellar liquid chromatography in the system "stationary phase-SAM micelle-water". The roles of the stationary phase and the micelle prior to watering are shifted in the matrix of the supersorbent "Solid water" (Fig. 6a). After watering, the solid phase is the soil (Fig. 6b) and the micelles are the diphilic fragments in the structure of the sorbent.

В соответствие с нашими представлениями все аналиты можно разделить по отношению к мицеллам в «Твердой воде» на четыре группы. К первой группе относят вещества, связывающиеся мицеллами, их подвижность возрастает с увеличением концентрации ПАВ в неподвижной фазе и коэффициент распределения между мицеллой и водой принимает значение $K_{M W}>0$. Вторая группа - это аналиты, не связывающиеся мицеллами при изменении концентрации ПАВ, и $K_{M W}=0$ [15]. Третью группу составляют анти-связывающие вещества, для которых с ростом концентрации ПАВ в подвижной фазе $K_{M W}<0$. Четвертую группу представляют высокомолекулярные аналиты с аномально высоким связыванием, в котором реагируют более одной мицеллы ПАВ (влияние «солевого эффекта» проявляется и $K_{M W}>>0$ ). Таким образом, распределение аналита по трехфазной модели зависит от всех трех коэффициентов распределения $\left(K_{S W}, K_{S M}, K_{M W}\right)$. Изменение коэффициентов распределения в значительной мере зависит от диэлектрической проницаемости растворителей $\varepsilon^{\circ}$ и определяет их элюирующую силу на твердых хроматографических носителях. В частности, элюотропный ряд для полиамидных сорбентов выглядит следующим образом $[14,17,20]$ (схема 5): 


\begin{tabular}{|c|c|c|c|c|}
\hline \multirow[t]{4}{*}{4} & Экстрагент & $\varepsilon^{\circ} / \varepsilon$ & Экстрагент & $\varepsilon^{\circ} / \varepsilon$ \\
\hline & \multirow{3}{*}{$\begin{array}{l}\text { Вода (полиамидная фаза } \\
\text { не смач. водой на } 100 \text { \%) }\end{array}$} & \multirow{3}{*}{$78.5 /-$} & Трибутилфосфат & $-/ 8.0$ \\
\hline & & & ТГФ & $7.4 /-$ \\
\hline & & & Этилацетат & $6.4 / 6.0$ \\
\hline \multirow{13}{*}{ 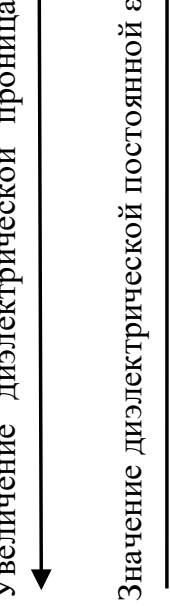 } & Глицерин & $47.0 /-$ & Хлорбензол & $-/ 5.9$ \\
\hline & Ацетонитрил & $37.5 /-$ & Хлороформ & $4.8 / 5.0$ \\
\hline & Нитрометан & $35.9 /-$ & Диизопропил. спирт & $3.9 /-$ \\
\hline & Нитробензол & $35.7 /-$ & Трихлорэтилен & $3.4 /-$ \\
\hline & Метанол & $32.6 /-$ & Толуол & $2.4 / 2.4$ \\
\hline & Этанол & $24.3 /-$ & Бензол & $2.3 / 2.3$ \\
\hline & Ацетон & $20.7 /-$ & 1,4-Диоксан & $2.2 /-$ \\
\hline & 1-Пропанол/2-пропанол & $20.1 / 18.3$ & $\mathrm{CCl}_{4}$ & $2.2 / 2.2$ \\
\hline & Метилэтилкетон & 18.5/11.9 & Циклогексан & $2.0 /-$ \\
\hline & 2-бутанол/н-бутанол & $17.8 / 7.8$ & н-Гептан & $2.0 /-$ \\
\hline & Пиридин & $12.3 /-$ & н-Гексан & $1.9 /-$ \\
\hline & Третбутанол & $12.2 /-$ & н-Пентан & $1.84 /-$ \\
\hline & Дихлорметан & $9.08 /-$ & Формамид & $-/-$ \\
\hline
\end{tabular}

Определение $K_{S W}, K_{S M}, K_{M W}$ для колоночной хроматографии соответствует уравнению $[13,15]$ :

$$
\frac{V_{S}}{V_{l}-V_{0}}=\frac{v\left(K_{M W}-1\right)}{K_{S W}} \cdot C_{M}+\frac{1}{K_{S W}}
$$

где $V_{S}$ - объем неподвижной фазы; $V_{l}$ - объем подвижной фазы; $V_{0}-$ «мертвый объем колонки»; $v$ - парциальный удельный объем ПАВ (мл/г) (для ДДС - $0.862 \mathrm{~cm}^{3} / \Gamma$ ); $C_{M}$ - концентрация мицелл в подвижной фазе $\left\{C_{M}=[C-K K M]\right\} ; C$ - общая концентрация ПАВ в подвижной фазе; $K K M$ - критическая концентрация мицеллообразования $\left(\Gamma / \mathrm{cm}^{3}\right)$.

Для тонкослойной хроматографии используется уравнение [13-15]:

$$
\frac{R_{f}}{1-R_{f}}=\frac{V_{M}}{V_{S}}\left(\frac{v\left(K_{M W}-1\right)}{K_{S W}}\right) \cdot C_{M}+\frac{V_{M}}{V_{S}} \frac{1}{K_{S W}} .
$$

где $R_{f}$ - подвижность сорбата; $V_{S}$ - объем неподвижной фазы; $V_{M}$ - объем подвижной фазы; $v$ - парциальный удельный объем ПАВ $\left(\mathrm{cm}^{3} / \Gamma\right) ; C_{M}-$ концентрация мицелл в подвижной фазе $\left\{C_{M}=[C-K K M]\right\} ; C$ - общая концентрация ПАВ в подвижной фазе;

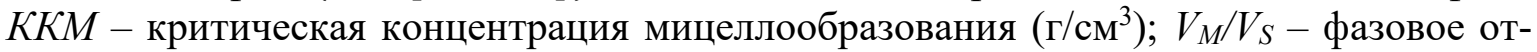
ношение [13-15].

В уравнениях 6 и 7 зависимости $V_{S} /\left(V_{l}-V_{0}\right)$ от $C_{M}$ и $R_{f} /\left(1-R_{f}\right)$ от $C_{M}$ являются линейными, что позволяет рассчитывать константу равновесных процессов из графических данных [20-21].

В случае графического варианта расчета для ТСX соотношение, описывающее зависимость удерживания $\left(R_{f}\right)$ от концентрации мицелл ПАВ $R_{f} /\left(1-R_{f}\right)=f\left(C_{M}\right)$, представляет собой уравнение прямой $y=a x+b$, в котором коэффициенты равны:

$$
\begin{gathered}
a=\frac{V_{M}}{V_{S}}\left[\frac{\left(K_{M V}-1\right) v}{K_{S W}}\right] ; \\
b=\frac{V_{M}}{V_{S}} \cdot \frac{1}{K_{S W}} .
\end{gathered}
$$


Перегруппировка к отношению $a / 8$, то есть к тангенсу угла наклона этой прямой (коэффициент $a$ ) к отрезку, отсекаемому на оси ординат (коэффициент 8 ), позволяет сократить в уравнении (7) величины $\left(V_{M} / V_{S}\right)$ и $K_{S W}$ и получить зависимость:

$$
\frac{a}{b}=\frac{V_{M} \cdot\left(K_{M W}-1\right) \cdot v \cdot K_{S W} \cdot V_{S}}{V_{S} \cdot K_{S M} \cdot V_{M}}=(K K M-1) \cdot v
$$

Тогда, измерив величину $R_{f}$ и построив графическую функцию $R_{f} /\left(1-R_{f}\right)=f\left(C_{M}\right)$, коэффициенты распределения сорбата между водной (дисперсионная среда) и мицеллярной фазами можно рассчитать по формуле [15, 20, 21]:

$$
K_{M W}=\frac{a}{b \cdot v}+1 .
$$

Коэффициент распределения $K_{S W}$ можно вычислить, используя выражение (9), а коэффициент $K_{S M}$ определяется как отношение двух предыдущих коэффициентов [15]:

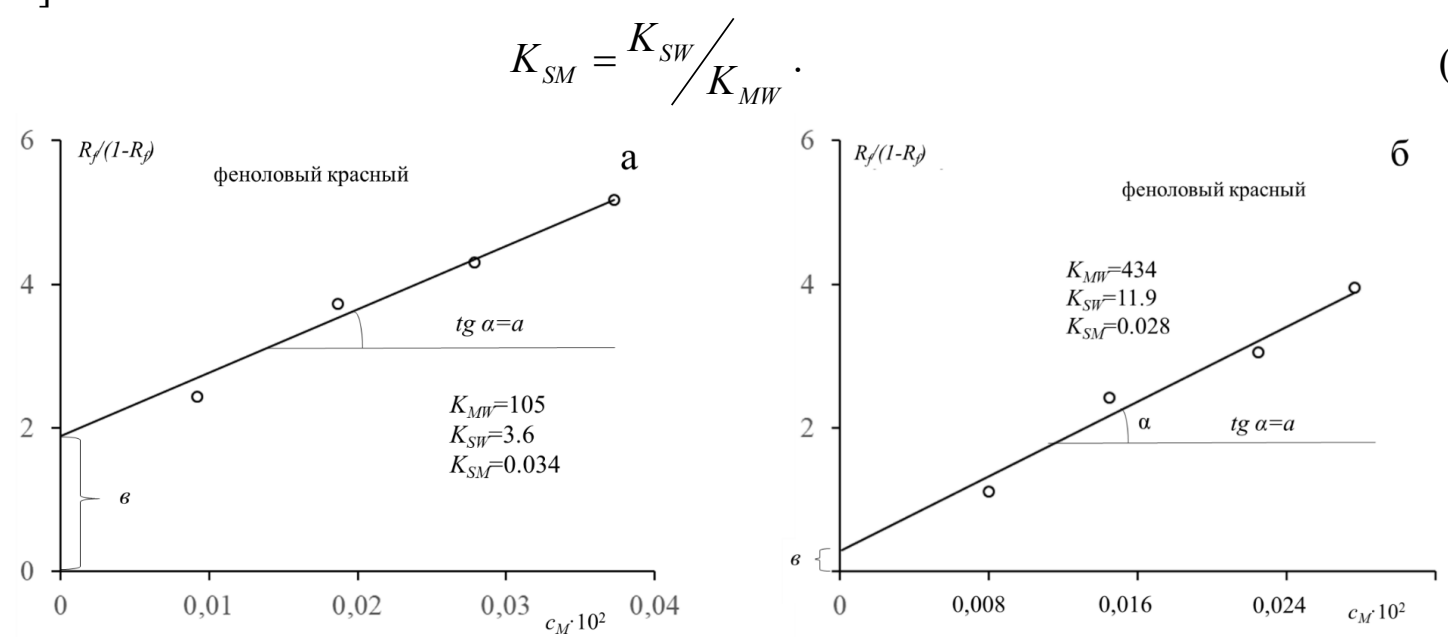

Рис. 7. Графическая зависимость $R_{f} /\left(1-R_{f}\right)$ от концентрации мицеллярной формы ПАВ в подвижной фазе $C_{M}$. а - Полиамид- 6 ; б - «Твердая вода»

Fig. 7. Dependence diagram of $R_{f} f\left(1-R_{f}\right)$ on the concentration of the micellar form of SAM in the mobile phase $C_{M}$. a - Polyamide- 6 ; b - "Solid water".

Представленные на рис. 7 и в табл. 5 данные позволяют сделать определенные выводы, касающиеся солюбилизации индикаторов в мицеллы додецилсульфата $\mathrm{H}_{3} \mathrm{C}-\left(\mathrm{CH}_{2}\right)_{11} \mathrm{SO}_{3} \mathrm{H}$ [13-17]. Значимым фактором, обусловленным гидрофобными взаимодействиями, является строение связываемого мицеллами сорбата. Кроме того, ассоциация индикаторов в ДДС, зависит от заряда ПАВ, природы ионамицеллобразователя, длины углеводородного радикала ПАВ. Об этом свидетельствуют результаты расчета коэффициентов распределения $K_{M W}$ между мицеллой и водой и $K_{S W}$ между неподвижной фазой и водой (рис. 7 и табл. 5).

Видно, что значения $K_{M W}$ превышают величины $K_{S W}$ для индикаторов ксантенового (флуоресцеин, эозин, эритрозин) и трифенилметнового рядов на 2 порядка. Аналогичный эффект четко проявляется при поглощении воды мицеллами ДДС фенолового красного редкосшитым сорбентом «Твердая вода» по сравнению с $K_{S W}$ в том случае, когда неподвижной фазой является сухая почва. На первом этапе увлажнения (поливе) приоритет по ассоциации воды принадлежит мицеллам. Только после этого происходит постепенное насыщение почвы влагой согласно очень малым значениям $K_{S M}$ между неподвижной фазой и мицеллами фенолового красного и -COOHгруппами в структуре абсорбента «Твердая вода» $[12,18,19]$. 
Таблица 5. Параметры уравнения (11) и коэффициенты распределения $K_{S W}, K_{S M}, K_{M W}$ реагентов из воды и неподвижной фазы в мицеллы ДДС [13-15]

Table 5. Parameters of the equation (11) and distribution coefficients $K_{S W}, K_{S M}, K_{M W}$ of the reagents from water and stationary phase to the micelles of SDS [13-15] * parameters for polyamide- $6 * *$ parameters for the sorbent "Solid water"

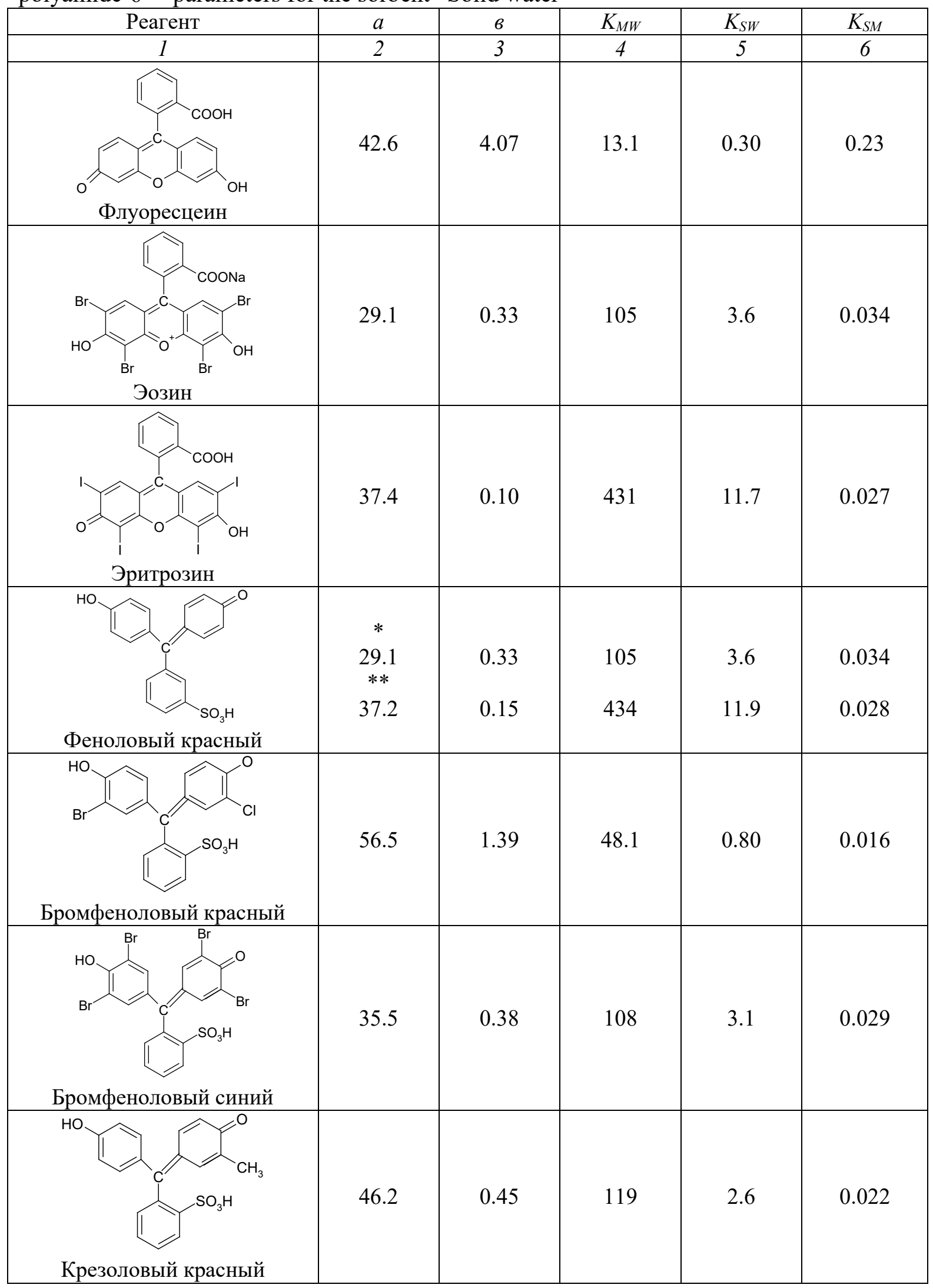

Селеменев и др. / Сорбционные и хроматографические процессы. 2020. Т. 20. № 4. С. 454-476 


\begin{tabular}{|c|c|c|c|c|}
\hline & 2 & 3 & 4 & 5 \\
\hline
\end{tabular}

*параметры для Полиамида-6;** параметры для сорбента «Твердая вода»

Следует также отметить, что присутствие атомов $\mathrm{Br}$ (эозин) и I (эритрозин) в молекулах реагентов ряда флуоресцеина значительно увеличивает константу связывания анионов индикаторов с мицеллами анионного ДДС. Совместное присутствие атомов галогенов и алкильных заместителей в индикаторах производных сульфофталеина приводит к росту их связывания с мицеллами додецилсульфата [13-16, 20].

V. Влияние $\mathrm{pH}$ на результаты разделения методом ТСX. В случаях хроматографирования соединений, проявляющих кислотно-основные свойства, методом TCX скорость движения по слою пластины зависит от следующих факторов: pH среды; констант протолиза $K_{a}$ (для кислот) и $K_{6}$ (для оснований); ионной силы раствора, коэффициентов распределения ионных и молекулярных форм. Уравнения, связывающие значения $R_{f}^{\prime}, R_{M}^{\prime}$, и $\mathrm{pH}$ в тонкослойной хроматографии имеет вид:

$$
R_{f}^{\prime}=1 /\left\{1+\left(A_{H \Phi} / A_{\Pi \Phi}\right) \cdot D \cdot\left[1+10^{\left(p H-p K_{a}\right.}\right]\right\},
$$

где $A_{H \Phi} / A_{\Pi \Phi}$ - фазовое отношение; $D$ - коэффициент распределения сорбата между подвижной и неподвижной фазами; $\mathrm{pK} \mathrm{a}_{\mathrm{a}}=-\lg \mathrm{K}_{\mathrm{a}}$.

$$
R_{M}^{\prime}=\lg D \cdot\left(A_{H \Phi} / A_{\Pi \Phi}\right)+\lg \left[1+10^{\left(p H-p K_{a}\right)}\right] .
$$

Из уравнений (13) и (14) видно, что с увеличением $\mathrm{pH}$ раствора величина $R_{f}^{\prime}$ снижается, а величина $R_{M}^{\prime}$ растет.

В случае оснований члены $\mathrm{pH}$ и $\mathrm{pK}_{\mathrm{a}}$ меняют знаки:

$$
R_{f}^{\prime}=1 /\left\{1+\left(A_{H \Phi} / A_{\Pi \Phi}\right) \cdot D \cdot\left[1+10^{\left(p K_{a}-p H\right.}\right]\right\} .
$$

Из представленных данных видно, что протолиты с различными значениями рК могут быть разделены даже тогда, когда все остальные параметры в ТСХ будут одинаковы [13-15].

Графическая зависимость $R_{f}$ от $\mathrm{pH}$ характеризуется точкой инверсии $\mathrm{pH}_{\mathrm{i}}$ (точкой перегиба) (рис. 8). Значение точки инверсии рассчитывается по уравнениям:

$$
p H_{i}=p K_{a}+\lg \left(K^{*} r+1\right) \text { (для кислот) }
$$




$$
p H_{i}=p K_{a}-\lg \left(K^{*} r+1\right) \text { (для оснований) }
$$

где $K^{*}{ }_{r}$ - величина обратная коэффициенту распределения $D\left(K^{*}=1 / D\right) ; r$ - величина

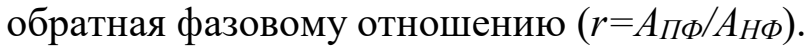

Из уравнений (16) и (17) следует, что $\mathrm{pH}_{\mathrm{i}}$ определяется константой протолиза и коэффициентом распределения сорбата. Для сильных растворителей имеется сдвиг $\mathrm{pH}_{\mathrm{i}}$ в область больших значений $R_{f}$ для кислот и в область меньших значений $R_{f}$ для оснований. Из представленных данных следует, что при хроматографическом определении $K_{a}$ по величинам $R_{f}$ и $\mathrm{pH}$ следует учитывать коэффициент распределения [13-15] (рис. 8).

Оптимальное значение $\mathrm{pH}$ при разделении двух протолитов определяют по уравнению:

$$
p H_{o p t}=\frac{1}{2}\left(p K_{a}^{\prime}+p K_{a}^{\prime \prime}\right)-\frac{1}{2}\left(\lg K^{* \prime} \cdot r+\lg K^{* \prime \prime} \cdot r\right) .
$$

Параметры использования уравнений (13-18) относятся и к нормальным и обращенным фазам. В первом случае буферный раствор является составляющей частью неподвижной фазы, во втором - подвижной.

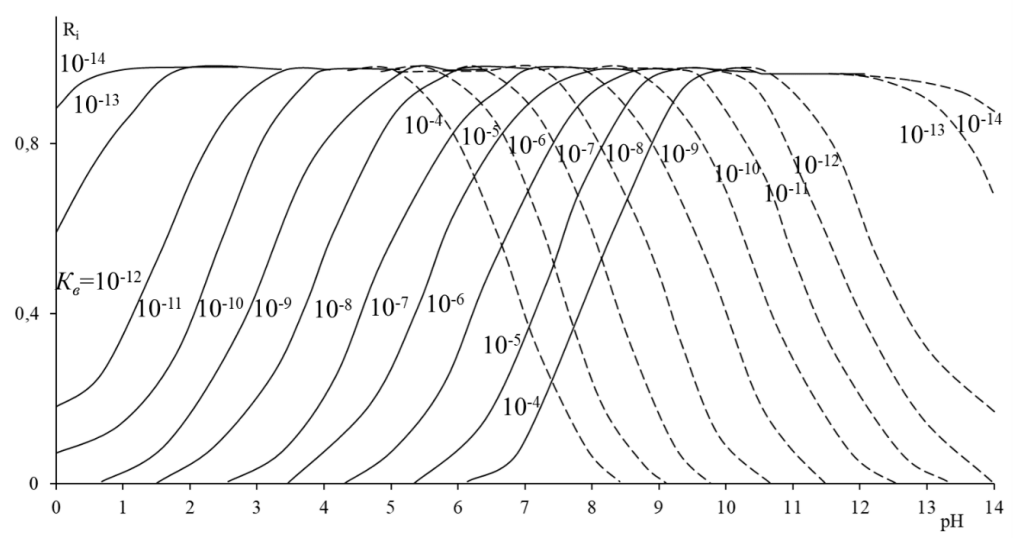

Рис. 8. Зависимость величины Ri от $\mathrm{pH}$.

Сплошные линии - основания; штрихпунктирные - кислоты

Fig. 8. Dependence of $R_{i}$ on $\mathrm{pH}$. Solid lines denote bases, and dot-and-dash lines denote acids.

Заслуживает внимания тот факт, что особое внимание по влиянию рН уделяется амфолитным ПАВ. Указанные соединения содержат функциональные группы и кислого и основного характера (например, карбоксильную и аминную группы). В зависимости от $\mathrm{pH}$ среды амфотерные ПАВ обладают либо катионными, либо анионными свойствами:

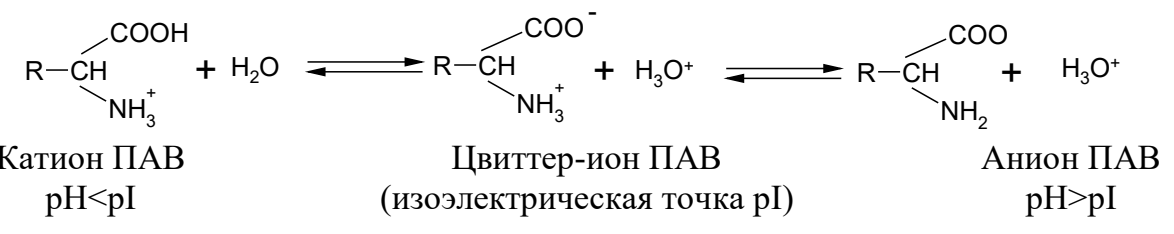

Наряду с ПАВ амфотерными свойствами могут обладать и неподвижные фазы (табл. 6), в том числе матрица сорбента «Твердая вода».

Влияние $\mathrm{pH}$ на индикаторы проявляется в том, что наряду с бензоидной, у них при изменении цвета проявляется хиноидная структура:

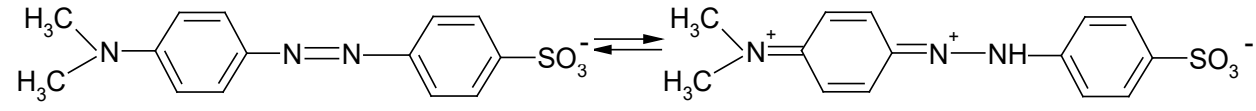


Таблица 6. Некоторые амфотерные носители в ТСX

Table 6. Some of the amphoteric carriers in TLC

\begin{tabular}{|c|c|c|}
\hline Название & Формула & $\begin{array}{c}\text { KКM, } \\
\text { мM }\end{array}$ \\
\hline Карбосипентадециламид & $\mathrm{C}_{2} \mathrm{H}_{5}^{-} \mathrm{OOC}-\left(\mathrm{CH}_{2}\right)_{15} \mathrm{~N}^{+} \mathrm{H}_{3}$ & - \\
\hline $\begin{array}{c}\text { Карбосипентадецил- } \\
\text { триметиламмоний бромид } \\
\text { (сентонекс) } \\
\end{array}$ & {$\left[\mathrm{C}_{2} \mathrm{H}_{5}-\mathrm{OOC}\left(\mathrm{CH}_{2}\right)_{15}-\mathrm{N}^{+}\left(\mathrm{CH}_{3}\right)_{3}\right] \mathrm{Br}^{-}$} & $\begin{array}{c}0.77- \\
1.6\end{array}$ \\
\hline $\begin{array}{c}\text { Цетиламид никотиновой } \\
\text { кислоты }\end{array}$ & $\mathrm{CH}_{3} \mathrm{COC}^{\prime}$ & - \\
\hline $\begin{array}{c}\text { Додецилметил- } \\
\text { аминоуксусная кислота }\end{array}$ & $\mathrm{C}_{12} \mathrm{H}_{25} \mathrm{~N}^{+}\left(\mathrm{CH}_{3}\right)_{2} \mathrm{CH}_{2} \mathrm{COO}^{-}$ & 1.8 \\
\hline Бетаины & & - \\
\hline Амидобетаины & & - \\
\hline $\begin{array}{c}\text { Этоксилированный амид } \\
\text { жирной кислоты }\end{array}$ & & - \\
\hline «Твердая вода» & & - \\
\hline
\end{tabular}

Это приводит к появлению цепи их чередующихся одинарных и двойных связей (цепь сопряжения или цепь конъюгации). В данном случае в системах при титровании идут процессы, которые приводят к самоорганизации под действием супрамолекулярных сил.

\section{Заключение}

В статье представлены результаты исследований по межмолекулярным взаимодействиям в полиамидах с участием воды, что позволило: уточнить механизм конформационных превращений в матрице полимеров; установить связь между положением полос в ИК-спектрах и структурой полиамидов; изучить сорбционные свойства полиамидов, в том числе и суперабсорбента «Твердая вода»; представить роль микрореакторов на основе мицелл поверхностно активных веществ; описать роль мицеллярных жидких фаз в экологических системах; рассчитать коэффициенты распределения в трехфазной модели мицеллярной хроматографии в системе неподвижная фаза-мицелла ПАВ-вода; изучить влияние $\mathrm{pH}$ на разделение компонентов в TCX-процессах.

Впервые определены положения в Полиамиде-6 и суперабсорбенте «Твердая вода» деформационных колебаний ножничных, веерных, маятниковых, торсионных. Установлено наличие димеров при реакции между двумя СООН-группами и циклических структур с участием связей Амид III.

Показано, что Н-связывание между фенолом и амидной группой полимеров происходит за счет взаимодействия фенольной ОН-группы с кислородом карбонильного фрагмента амидного звена полиамидной цепи полимера.

Представлены механизмы совмещения процесса регенерации полиамида после поглощения фенола с элюентным вариантом хроматографического выделения 
целевого вещества. Наиболее эффективна десорбция фенола растворами этанола и ацетона.

Предложены формы изотерм процесса мицеллообразования для сорбатов в зависимости от соотношения эффективных поверхностей $S_{c}$ и дифильной молекулы $S_{M}$ ПАВ вблизи точки ККМ. Превышение концентрации поверхностно активным веществом величин ККМ приводит к росту концентрации смешанных мицелл в неподвижной и подвижной фазах ТСХ.

Предложена гипотеза разделения полярных и неполярных аналитов в связи с возникновением наногетерогенных мицеллярных подвижных фаз с элементами самоорганизации.

Обсуждена возможность поглощения воды сухой почвой как вторичного процесса при наличии в мицеллах ПАВ фазы суперабсорбента «Твердая вода» жидкокристаллических ламинарных и кристаллических структур, для которых характерны коэффициенты распределения $K_{M W}$ на несколько порядков превышающие значения коэффициентов распределения $K_{S M}$ между почвой и растворителем.

Рассчитаны коэффициенты распределения $K_{M W}$ между мицеллой фенолового красного и водой; $K_{S W}-$ между неподвижной поверхностью и водой; $K_{S M}-$ между неподвижной фазой и модификатором для Полиамида -6 и суперабсорбента «Твердая вода».

Установлены оптимальные параметры разделения ионов и молекул индикаторов-протолитов для ТСХ с нормальной и обращенной фазами. При хроматографическом определении констант протолиза кислот и оснований по величинам $R_{f}$ и $\mathrm{pH}$ следует учитывать величины коэффициентов их распределения между подвижной и неподвижной фазами.

Авторы статьи единогласно согласились с тем, что полученные результаты по межмолекулярным взаимодействиям с участием воды в подвижной (ПФ) и неподвижной (НФ) фазах полиамидов будут способствовать внедрению этого класса полимеров для использования в анализе и разделении органических веществ хроматографическими методами.

Работа выполнена при поддержке Министерства науки и высшего образования РФ в рамках государственного задания ВУЗам в сфере научной деятельности на 2020-2022 годы, проект № FZGU-2020-0044.

\section{Список литературы}

1. Дехант И., Данц Р., Киммер В., Шмольке Р. Инфракрасная спектроскопия полимеров. М. Химия. 1976. $472 \mathrm{c.}$

2. Беккер Ю. Спектроскопия. М. Техносфеpa. $2009.528 \mathrm{c}$.

3. Тиноко И., Зауэр К., Вэнг Дж. Физическая химия. Принципы и применение в биологических науках. М. Техносфера. 2005. 743 c.

4. Bull H.B., Brese K. // Arch. Biocem. Fnd Biophys. 1968. Vol. 128. pp. 488-496.

5. Пиментел Дж., Мак-Клеллан. Водородная связь. М. Мир. 1964. 462 с.

6. Селеменев В.Ф., Котова Д.Л., Орос Г.Ю. Загородний А.А. // в кн. «100 лет хроматографии». М. Наука. 2003. С. 546-569.
7. Беккер Ю. Хроматография. Инструментальная аналитика: методы хроматографии и капиллярного электрофореза. М. Техносфеpa. $2009.472 \mathrm{c}$.

8. Углянская В.А., Чикин Г.А., Селеменев В.Ф., Завьялова Т.А. Инфракрасная спектроскопия иоонообменных материалов. Воронеж. ВГУ. 1989. 208 с.

9. Жеребцов Н.А., Попова Т.Н., Артюхов В.Г. Биохимия. Воронеж. ВГУ. 2002. 696 с.

10. Цундель Г. Гидратация и межмолекулярное взаимодействие. М. Мир. 1972. 404 с.

11. Селеменев В.Ф. Дисс. д-ра хим. наук. Воронеж. 1993. 602 с. 
12. Зенищева А.В., Семенов В.Н., Кузнецов В.А., Кущев П.О. // Конденсированные среды и межфазные гранищьл. 2020. №1. С. 66-74.

13. Сумина Е.Г., Штыков С.Н., Тюрина Н.В. Основы модифицирующего действия поверхностно-активных веществ в жидкостной хроматографии. Саратов. ФАЩРФ Саратовский университет. 2006. 136 с.

14. Сумина Е.Г. // в кн. «Нанообъекты и нанотехнологии в химическом анализе». М. Наука. 2015. С. 267-305.

15. Сумина Е.Г., Штыков С.Н., Тюрина Н.В. Основы модифицирующего действия поверхностно-активных веществ в жидкостной хроматографии. Учебн. пособие. Саратов. Изд-во Саратовского университета. 2006. $101 \mathrm{c}$.
16. Штыков С.Н. // в кн. «Люминесцентный анализ. Проблемы аналитической химии». М. Наука. 2015. Т. 19. С. 121-146.

17. Чернова Р.К., Доронин С.Ю. Определение органических аналитов в растворах ПАВ: ионные и мицеллярные эффекты. Саратов. Изд-во Саратовского университета. 2017. $1200 \mathrm{c}$.

18. Кузнецов В.А., Кущев П.О. Патент РФ. № 2569377-C1. 2015.

19. Кузнецов В.А., Селеменев В.Ф., Семенов В.Н., Бакалова М.В. Патент РФ. № 2574722. 2016.

20. Сумина Е.Г., Штыков С.Н., Тюрина Н.В. // Сорбционные и хроматографические проиессы. 2004. Т.4. № 6. С. 750-756.

21. Бронштейн И.Н., Семендяев К.А. Справочник по математике для инженеров и учащихся ВТУзов. М. Наука. 1886. С. 11-209.

\title{
Intermolecular interactions in polyamides involving water
}

\author{
(C)2020 Selemenev V.F. ${ }^{1}$, Karpov S.I. ${ }^{1}$, Belanova N.A. ${ }^{1}$, Rudakova L.V. ${ }^{2}$, \\ Semenov V.N. ${ }^{1}$, Kuschev P.O. ${ }^{1}$, Sinyaeva L.A. ${ }^{1}$ \\ Voronezh State University, Voronezh \\ Voronezh state medical University named after N.N. Burdenko, Voronezh
}

The article specifies the classification of adsorption bands in the IR spectra of polyamides. The study revealed the presence of wagging, scissoring, rocking, and twisting which are characteristic of the structures in amide I, amide II, amide III, amide IV, amide V, and amide VI.

The IR spectroscopy demonstrated the presence of cyclic structures in the polyamide- 6 and the supramolecular sorbent "Solid water". The cyclic structures were formed by carbocylic groups: $-\mathrm{C}>\mathrm{O}-\mathrm{O}-\mathrm{H}-\mathrm{O}$

in neighbouring parallel chains as a result of tautomeric transformations (involving

amide groups) of lactam fragments:

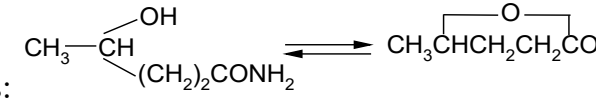

The study also demonstrated that polyamides can absorb phenol and its derivatives from aqueous solutions. This sorption is quite active since phenol forms stronger hydrogen bonds with $\mathrm{C}=\mathrm{O}$ groups of amide

groups than with $-\mathrm{NHCO} \cdots \mathrm{H}_{2} \mathrm{O}$ and<smiles></smiles>

The article suggests a modification principle of the triad of interacting components "water - micellar microreactor with surface-active material (SAM) - stationary phase". The characteristic feature of the supersorbent "solid water" is that when it is sown in dry soil and watered once, the stationary phase is the micelle modified with SAM. The surface-active material acts as a crystallite and as a liquid phase with laminar structure.

The study demonstrated that in a three-component model, the key role belongs to the coefficient $\left(K_{M W}\right)$ of distribution between the micelle and water, as well as the coefficient of distribution $\left(K_{S M}\right)$ in the stationary phase (SP). Of much less importance in the three-component model is the coefficient of distribution $\left(K_{S W}\right)$ between the stationary phase and water, since $K_{S W}$ is two and more times smaller than $K_{M W}$.

The study also provided the information about the interaction of the micelles of SAM, which are protolytes that exist in the cation form ${ }^{\mathrm{R}-\mathrm{CH}_{\mathrm{N}} \mathrm{H}_{3}} \quad(\mathrm{pH}<\mathrm{pI})$ in acidic media; in the form of bipolar ions ${ }^{\mathrm{R}}-\mathrm{NH}_{3} \quad(\mathrm{pH}=\mathrm{pI})$ in neutral media (with $\mathrm{pH}=\mathrm{pI}$, where $\mathrm{I}$ is an isoelectric point); and in the form of aniones 
$\mathrm{R}-\stackrel{\mathrm{CH}}{\mathrm{HH}}_{\mathrm{NOO}_{2}}^{-}$

$(\mathrm{pH}>\mathrm{pI})$ in the media with high $\mathrm{pH}$ values. In protolytic reactions, they appear with indicators and initiate the transitions of benzol structures into quinoid ones and result in the appearance of conjugation chains with alternating single and multiple bonds.

The article also provides data demonstrating the influence of the distribution coefficients $K_{L}$ in the mobile (MP) and stationary phases (SP) of TLC on the protolysis constants $K_{a}$ of the separated components and on the $\mathrm{pH}$ in micellar reactors.

We believe that polyamides, along with other polymers, will play a significant role as stationary phases in planar chromatography and high-performance liquid chromatography.

Keywords: polyamides, intermolecular interactions, IR spectroscopy, UV spectroscopy.

\section{References}

1. Dekhant I., Dants R., Kimmer V., Shmol'ke R. Infrakrasnaya spektroskopiya polimerov, M., Khimiya, 1976, 472 p.

2. Bekker Yu. Spektroskopiya, M., Tekhnosfera, 2009, 528 p.

3. Tinoko I., Zauer K., Veng Dzh., Fizicheskaya khimiya. Printsipy i primenenie v biologicheskikh naukakh, M., Tekhnosfera, 2005, 743 p.

4. Bull H.B., Brese K., Arch. Biocem. Fnd Biophys, 1968, Vol. 128, pp. 488-496.

5. Pimentel Dzh., Mak-Klellan, Vodorodnaya svyaz', M., Mir, 1964, 462 p.

6. Selemenev V.F., Kotova D.L., Oros G.Yu. Zagorodnii A.A., v kn. «100 let khromatografii». Mo., Nauka, 2003, pp. 546-569.

7. Bekker Yu., Khromatografiya. Instrumental'naya analitika: metody khromatografii i kapillyarnogo elektroforeza, M., Tekhnosfera, 2009, 472 p.

8. Uglyanskaya V.A., Chikin G.A., Selemenev V.F., Zav'yalova T.A., Infrakrasnaya spektroskopiya ioonoobmennykh materialov, Voronezh, VGU, 1989, 208 p.

9. Zherebtsov N.A., Popova T.N., Artyukhov V.G., Biokhimiya, Voronezh, VGU, 2002, 696p.

10. Tsundel' G. Gidratatsiya i mezhmolekulyarnoe vzaimodeistvie. M., Mir, 1972, 404 p.

11. Selemenev V.F. Diss. d-ra khim. nauk. Voronezh, 1993, 602 p.

12. Zenishcheva A.V., Semenov V.N., Kuznetsov V.A., Kushchev P.O., Kondensirovannye

Селеменев Владимир Федорович - д.Х.н., проф. каф. аналитической химии, Воронежский государственный университет, Воронеж

Карпов Сергей Иванович - к.Х.н., доцент каф. аналитической химии, Воронежский государственный университет, Воронеж sredy $i$ mezhfaznye granitsy, 2020, No 1, pp. 6674. DOI: $10.17308 / \mathrm{kcmf} .2020 .22 / 2530$.

13. Sumina E.G., Shtykov S.N., Tyurina N.V., Osnovy modifitsiruyushchego deistviya poverkhnostno-aktivnykh veshchestv v zhidkostnoi khromatografii, Saratov, FAShchRF Saratovskii universitet, 2006, $136 \mathrm{pp}$.

14. Sumina E.G., v kn. "Nanoob"ekty $i$ nanotekhnologii $v$ khimicheskom analize», M., Nauka, 2015, pp. 267-305.

15. Sumina E.G., Shtykov S.N., Tyurina N.V., Osnovy modifitsiruyushchego deistviya poverkhnostno-aktivnykh veshchestv $\mathrm{v}$ zhidkostnoi khromatografii, Uchebn. posobie. Saratov, Izdvo Saratovskogo universiteta, 2006, 101 p.

16. Shtykov S.N., $v k n$. «Lyuminestsentnyi analiz. Problemy analiticheskoi khimii», M., Nauka, 2015, Vol. 19, pp. 121-146.

17. Chernova R.K., Doronin S.Yu., Opredelenie organicheskikh analitov $\mathrm{v}$ rastvorakh PAV: ionnye i mitsellyarnye effekty, Saratov, Izd-vo Saratovskogo universiteta, 2017, 1200 p.

18. Kuznetsov V.A., Kushchev P.O. Patent RF, No 2569377-S1, 2015.

19. Kuznetsov V.A., Selemenev V.F., Semenov V.N., Bakalova M.V. Patent RF, No $2574722,2016$.

20. Sumina E.G., Shtykov S.N., Tyurina N.V., Sorbtsionnye i khromatograficheskie protsessy. 2004, Vol. 4, No 6, pp. 750-756.

21. Bronshtein I.N., Semendyaev K.A. Spravochnik po matematike dlya inzhenerov $\mathrm{i}$ uchashchikhsya VTUzov. Moskva, Nauka, 1886, pp. 11-209.

Selemenev Vladimir F. - DSc in chemistry, Voronezh State University, Voronezh, Russian Federation, e-mail: common@chem.vsu.ru

Karpov Sergey I. - PhD in Chemistry, the senior lecturer of the department of Analytical Chemistry, Voronezh State University, Voronezh, Russian Federation; e-mail: karsiv@mail.ru 
Беланова Наталья Анатольевна - к.Х.Н., ассистент каф. аналитической химии, Воронежский государственный университет, Воронеж

Рудакова Людмила Васильевна - д.х.н., профессор, заведующая кафедрой фармацевтической химии и фармацевтической технологии, Воронежский государственный медицинский университет им. Н.Н. Бурденко, Воронеж

Семенов Виктор Николаевич - д.Х.н., профессор, заведующий кафедрой общей и неорганической химии, Воронежский государственный университет, Российская Федерация

Кущев Петр Олегович - к.Х.Н., ассистент каф. высокомолекулярных соединений и коллоидной химии, Воронежский государственный университет, Российская Федерация

Синяева Лилия Александровна - к.Х.н., ведущий инженер кафедры аналитической химии Воронежского государственного университета, Воронеж
Belanova Natalya A. - PhD in Chemistry, the assistant of the department of Analytical Chemistry, Voronezh State University, Voronezh, Russian Federation; e-mail: belanovana@mail.ru

Rudakova Lyudmila V. - Doctor of Chemistry, Full Professor, Head of the Department of Pharmaceutical Chemistry, Voronezh state medical University named after N.N. Burdenko, Voronezh, Russian Federation; e-mail: vodoley65@mail.ru

Semenov Victor N. - Doctor of Chemistry, Full Professor, Head of the Department of General and Inorganic Chemistry, Voronezh State University, Voronezh, Russian Federation; e-mail: semenov@chem.vsu.ru

Kuschev Petr O. - PhD in Chemistry, the assistant of the department of Polymer Science and Colloid Chemistry, Voronezh State University, Voronezh, Russian Federation; e-mail: peter.kuschev@gmail.com

Sinyaeva Liliia A. - PhD in Chemistry, the senior engineer, department of Analytical Chemistry, Voronezh State University, Russian Federation; email: liliya.sinyaevavsu@mail.ru 